Dynamics and Earthquake Engineering

Elsevier Editorial System(tm) for Soil Manuscript Draft

Manuscript Number: SOILDYN-D-15-00472R4

Title: Influence of air injection on the liquefaction-induced deformation mechanisms beneath shallow foundations

Article Type: Research Paper

Keywords: Geotechnical centrifuge; Air injection; Shallow foundations; Liquefaction-induced deformations

Corresponding Author: Mr. ABDULHAKIM ZEYBEK,

Corresponding Author's Institution: CAMBRIDGE UNIVERSITY

First Author: ABDULHAKIM ZEYBEK

Order of Authors: ABDULHAKIM ZEYBEK; Gopal S Madabhushi, MTech, PhD 
The authors would like to thank the reviewers again for their time and additional comments. Based on the comments, we have attempted to cover all of their points and made changes of the manuscript, which are detailed below.

\section{Reviewer 2:}

The submitted manuscript presents very valuable information about the liquefaction induced deformation mechanism under the foundation in fully as well as well in partially saturated sands. However, the originality of the paper concerns me since there are figures and content published in another technical paper ("Centrifuge testing to evaluate the liquefaction response of air-injected partially saturated soils beneath shallow foundations" which has just been published in Bulletin of Earthquake Engineering). I would consider this manuscript as a technical note where most of the figures are not included and referred to the published article.

The published manuscript and the submitted manuscripts presented the results from the same centrifuge tests. The results were just presented in different manners. There are same figures presented in both manuscripts as below:

In the first and second round of revision, the authors were invited to revise the manuscript to address a number of technical comments. In the third round of revision, the most significant issue that has been raised by the reviewer is the originality of the paper. The authors believe that the changes made in the submitted manuscript do go a long way to ensuring that the main concern of the reviewer is addressed within the paper itself.

Following the reviewer's comments, the manuscript has been changed significantly. A dataset from a series of two free-field centrifuge tests is included (see the amended Table 1). It is worth stating that the free-field test data has not been published elsewhere. The vast majority of the figures submitted in the second round of revised manuscript are replaced by the original figures. Accordingly, the relevant sections have been rewritten. The content of the paper has been significantly improved by adding more comprehensive discussions and a new dataset. The authors wish to thank the reviewers for this.

\section{1- Figure 1 in both manuscripts show the same experimental setup.}

Answer 2.1- The cross-section of the models is modified following the comment of the reviewer, as given in Fig. 1 in this round of revised paper.

\section{2- Fig. 2 in published manuscript vs Fig. 6 in submitted manuscript.}

Answer 2.2-Following the reviewer's comment, the acceleration time histories in the previous manuscript (Fig. 6) are removed from the manuscript and replaced by the shear stress- strain loops, as presented in Fig. 7 in the this round of revised paper. The effect of air injection on the shear stiffness of soil is demonstrated. It is noted that Fig. 2 in the published paper showed only the input (base) acceleration time histories recorded during the tests, whereas Fig. 6 submitted in the second round of revised manuscript presented the horizontal acceleration time histories recorded at different soil layers.

\section{3- Fig.3 in published manuscript vs Fig. 5 in submitted manuscript. They both demonstrated the} average settlements.

Answer 2.3- The average displacements recorded at the soil surface are added, as presented in Fig. 10 in this round of revised paper. The discussion about the foundation settlement and free-surface settlement is extended further. The focus of the relevant sections is placed onto different aspects of soil behaviour, which are very different from the published paper.

2.4- Fig. 5 in published manuscript vs Fig. 8 in submitted manuscript. Fig. 8 gives the excess pore pressures for $135 \mathrm{kPa}$. The ones given in the final revision is more correct than the ones in the published manuscript since it includes now the foundation induced stresses in ru calculation.

Answer 2.4- The excess pore pressure time histories recorded in the tests with heavy shallow foundation (135 $\mathrm{kPa}$ bearing pressure) are removed from the manuscript, following the reviewer's comment. Instead, the variation of excess pore pressure ratios with depth and the distance from the air 
injector is depicted in Fig. 9. The excess pore pressure ratio contours are drawn based on the peak values of excess pore pressures generated during earthquakes at the locations of PPTs. In this analysis, the foundation-induced stresses are accounted for.

\section{5- The left hand side figure of the Fig. 14 and the figures (a) and (c) in Fig. 11 in the submitted manuscript. They both show the deformation mechanisms.}

Answer 2.5- The relevant displacement vectors are removed from the manuscript. Instead, the contours of horizontal, vertical and total soil displacements are added for the free-field tests in Fig. 6 and for the tests with foundations in Fig. 11. The displacement vector fields corresponding to the cycle by cycle based analysis are depicted in one figure (Fig. 12) for the whole foundation tests.

\section{Regarding the originality of the paper}

Within the confines of the authors' research, the prevailing deformation mechanisms that generate the ground surface and foundation settlement in the saturated or partially saturated soils are studied. The compiled dataset has shown us that the contribution of each settlement-producing deformation mechanism depends on several parameters associated with the properties of the liquefiable layer (e.g., density and degree of saturation) the features of the examined foundation (e.g., foundation bearing pressure) and ground motion characteristics (e.g., magnitude, frequency and duration of input motion). The effects of each parameter on the deformation mechanisms have been investigated exclusively during the course of their research programme.

The published paper had its focus on showing the effects of degree of saturation and bearing pressure on the soil \& foundation response and displacement mechanisms. Degree of saturation $(\mathrm{Sr})$ and bearing pressure $(q)$ are shown to alter the shape and size of the displacement mechanisms. The partially saturated soils with different $S r$ and $q$ produce different displacement mechanisms.

By their very nature, research papers based on experimental work have same commonality. For instance, model cross-sections, input motions, experimental setup and its description will be similar among papers, and this is quite common. Nevertheless, the emphasis of this paper, which is on the deformation mechanism during air injection and co-seismic \& post-seismic period, is quite different to the previously published work in the Bulletin of Earthquake Engineering. The authors have taken the reviewers' comments positively, and have changed the figures and text where necessary, for example plotting displacement and excess pore pressure contours, as opposed to showing time histories. This, we believe, does improve the paper and shows the experimental data in different aspects. All in all, the novel contributions of this manuscript can be listed as:

-It explicitly identifies the most critical deformation mechanisms in the partially saturated soils during air injection, during and after earthquake (Table 2). Particularly, the deformations during air injection and resulting mechanisms have not been published elsewhere.

-It offers insights into the way that the deformation mechanisms which dominate the settlement of shallow foundations and free-field ground surface change dramatically with the injection of air (section 3.1 and 3.3). The deformations changing in a cycle by cycle basis (e.g., variation of magnitude and rate of displacement \& corresponding settlements with each cycle) have been first time shown in this paper using the PIV-based displacement vectors (Fig. 12).

-The shear stiffness of soil increases as a result of air injection (Fig. 7).

-Confining stress level and the distance to the air injector (extend of air-entrapped zone) are found to be important parameters for consideration in design practice (Fig. 9). 
1. Air injection is successful to minimize the liquefaction-induced deformations.

2. Stress level and size of air-entrapped zone affect the efficacy of this technique.

3. Injection of air into soils alters the dominant mechanism of deformation.

4. Deviatoric and volumetric strains cause large foundation settlements.

5. Deviatoric-induced deformations are notably reduced by air injection. 


\title{
Influence of air injection on the liquefaction-induced deformation mechanisms beneath shallow foundations
}

\author{
A. Zeybek ${ }^{\mathrm{a}^{*}}$, S.P.G. Madabhushi ${ }^{\mathrm{b}}$ \\ ${ }^{\text {a }}$ Schofield Centre, University of Cambridge, CB3 0EL, UK, Tel: +447411787353, Email: az323@ cam.ac.uk \\ ${ }^{\mathrm{b}}$ Department of Engineering, University of Cambridge, CB2 1PZ, UK, Tel: +44 (0) 1223768053, Email: mspg1@ cam.ac.uk
}

\begin{abstract}
Earthquake-induced liquefaction of soils frequently causes serious damage to structures with shallow foundations. Reducing the degree of saturation of liquefiable soils by air injection is offered as a cost-effective and reliable method of mitigating liquefaction hazards. Nevertheless, very little experimental research is available on the performance of this method. Particularly, the way that air injection influences the deformation mechanisms beneath shallow foundations is not well defined. Gaining a deeper insight into soil displacements during and after air injection can pave the way for developing effective guidelines for the use of this particular technique. For this purpose, a series of dynamic centrifuge tests are presented in this paper. The prevailing deformation mechanisms are identified in a novel way using displacement vector fields. The results indicate that air injection alters the deformation mechanisms that develop underneath and in the ground surrounding a shallow foundation, substantially reducing the average settlements.
\end{abstract}




\section{Introduction}

Seismically-induced liquefaction of soils has caused many structures with shallow foundations to suffer severe damage during most moderate to large earthquakes. Some of the prime examples of this are the recent earthquakes in Turkey [1], Chile [2] and Japan [3]. For many years, engineers have conducted several research programmes to develop different types of liquefaction mitigation techniques. A brief list of currently available liquefaction mitigation techniques is given by Seed et al. [4]. These techniques are usually not employed singly, but the combination of two or more is used in practice. The majority of these techniques are often expensive due to their installation costs, and their applications to foundation soils of existing structures are limited. In recent years, many researches have therefore directed their attention towards the development of new liquefaction mitigation techniques that can be implemented beneath the foundation of existing structures as well as at new construction sites.

Natural soils below ground water table are typically considered to be fully or nearly fully saturated [5]. However, partially saturated soils that have formed as a result of biological activities can be also encountered in nature [6]. The degree of saturation, $S_{r}$ of these soils is relatively low compared to fully saturated soils, and the reduction in the degree of saturation is attributed to the presence of retained air bubbles within the voids of soil. The influence of degree of saturation on the liquefaction resistance of soils has been investigated by several researchers through laboratory tests [7-8]. The test results have demonstrated that the liquefaction potential of saturated soils can be markedly decreased by even a small amount of reduction in the degree of saturation. In the light of these findings, recently attempts have been made to lower the degree of saturation of liquefiable soil deposits by artificially introducing gas bubbles into soils. Several methods have been used for this purpose, including water electrolysis [9], drainage-recharge [9-10], chemical- sodium perborate [11] and biogas [12].

Air injection is another technique that is used for lowering the degree of saturation. This approach basically relies on artificially injecting air into saturated, liquefiable soils without causing significant hydrofracture. Investigations on this particular technique have revealed that injection of air into soil deposits can substantially reduce the degree of saturation [13- 
14]. The longevity of air bubbles in the soil was studied by Eseller-Bayat et al. [11] and Okamura et al. [15]. It is shown that air bubbles introduced into saturated soil can remain entrapped for a long period of time and do not dissipate easily, which makes this technique reliable. Air injection is a cost-effective and eco-friendly liquefaction mitigation technique since it requires only the use of air, and its impact on the environment is insignificant [16]. These facts have recently led this particular technique to be greatly attractive for researchers and engineers. The application of this technique in practice such as beneath an existing embankment was demonstrated by Okamura et al. [17]. The research particularly investigating the response of shallow foundations resting on the liquefiable soils has suggested that the liquefaction potential of soil deposits and relevant foundation settlements significantly decrease with the injection of air [18-19]. The increase in the liquefaction resistance of soils is attributed to the presence of air in the voids of soil. Air in the pores decreases the bulk modulus and increases the compressibility of pore fluid which is air-water mixture. During shaking, the existing air absorbs the generated excess pore pressures by reducing in volume [8].

The previous studies have proven that air injection technique can be an effective way of minimizing the liquefaction-induced foundation settlements. Nevertheless, a comprehensive understanding of the way that air injection affects the seismic response of soils and foundations is still required. In reality, very little experimental research is available as to what the displacement mechanisms beneath and around the edges of shallow foundations resting on partially saturated soils resemble. Therefore, more research is wanting. Gaining a deeper insight into soil displacements can provide better estimation of the extend of liquefaction mitigation needed as well as the potential soil and foundation deformations (e.g., magnitude and rate of settlement and rotations). This eventually can pave the way for developing effective guidelines for air injection technique, and this can allow the engineers to use it in the field more confidently and more often. As part of this research, a spectrum of parameters that influence the soil deformations including degree of saturation and foundation bearing pressure were investigated separately by Zeybek and Madabhushi [20]. The aim of the current paper is to identify the deformation mechanisms that involve in the saturated and partially saturated soils. Of particular interest is the way that the deformation mechanisms which dominate the settlement of shallow foundations supporting typical structures change depending on the presence of air bubbles in the soil deposits. For this purpose, the derived 
displacement vector fields from the saturated and partially saturated soil layers are presented, and the corresponding results are compared. It is hoped to reinforce and build on the previous research with the findings presented in this paper.

\section{Centrifuge testing programme}

Geotechnical centrifugal modelling offers an opportunity of testing small-scale models under increased gravitational field and recreating prototype stresses and strains, which in turn replicates the true soil behaviour. A series of five centrifuge experiments were performed on the Turner Beam Centrifuge at the Schofield Centre of the University of Cambridge. More details about the geotechnical centrifuge facilities and instrumentation are provided by Madabhushi [21]. Centrifuge models, representing plain strain problems, were prepared and spun at a nominal centrifugal acceleration of $70 \mathrm{~g}$. Unless otherwise indicated, all units presented in this paper are in prototype scale. A $3.5 \mathrm{~m}$ wide shallow foundation model with a bearing pressure of $135 \mathrm{kPa}$, representing a strip footing of a heavy structure, was considered. Two bench-mark centrifuge experiments were performed in order to investigate the seismic response of nearly fully saturated (unimproved) soils in the free-field and beneath the shallow foundation. It is highlighted that for the remainder of this paper the term 'saturated soil' is used in direct reference to the nearly fully saturated soil. In a similar way, the seismic behaviour of partially saturated soils (improved by air injection) was studied undertaking three centrifuge tests. Table 1 provides a summary of the centrifuge test parameters and testing programme.

Table 1 Centrifuge test parameters and testing programme.

\begin{tabular}{|c|c|c|c|c|c|c|c|}
\hline \multirow[b]{2}{*}{$\begin{array}{l}\text { Test } \\
\text { ID }\end{array}$} & \multirow[b]{2}{*}{$\begin{array}{l}\text { Model } \\
\text { identification }\end{array}$} & \multicolumn{3}{|c|}{ Test conditions } & \multicolumn{3}{|c|}{ Earthquake parameters } \\
\hline & & $\begin{array}{l}\text { Initial } \\
\text { relative } \\
\text { density } \\
D_{r}(\%) \\
\end{array}$ & $\begin{array}{l}\text { Residual } \\
\text { degree of } \\
\text { saturation } \\
S_{r}(\%) \\
\end{array}$ & $\begin{array}{l}\text { Foundation } \\
\text { bearing } \\
\text { pressure } \\
q(\mathbf{k P a}) \\
\end{array}$ & $\begin{array}{l}\text { Frequency } \\
(\mathrm{Hz})\end{array}$ & $\begin{array}{l}\text { Duration } \\
\text { (s) }\end{array}$ & $\begin{array}{l}\text { Peak input } \\
\text { acceleration } \\
\text { (g) }\end{array}$ \\
\hline FS-1 & Saturated & 40.1 & 99.0 & 135.0 & 0.72 & 28 & 0.18 \\
\hline PS-1 & Partially saturated & 39.7 & 89.0 & 135.0 & 0.72 & 28 & 0.18 \\
\hline PS-2 & Partially saturated & 39.8 & 86.0 & 135.0 & 0.72 & 28 & 0.18 \\
\hline FS-2 & Saturated & 40.3 & 99.0 & Free-field & 0.72 & 28 & 0.18 \\
\hline PS-3 & Partially saturated & 40.1 & 86.6 & Free-field & 0.72 & 28 & 0.18 \\
\hline
\end{tabular}




\subsection{Model preparation}

The choice of model container for this study was dictated by the need to have a transparent side to conduct high speed photogrammetry. Therefore, a rigid container with a Perspex window was used. This type of model container may cause boundary effects due to its rigid walls and therefore affect the model response, particularly when liquefaction is reached. Therefore, a soft putty-like material called Duxseal ${ }^{\circledR}$ was used at the container end walls to minimize the boundary effects in the direction of earthquake loading. Steedman and Madabhushi [22] showed that Duxseal can reduce the stress wave reflections by about twothirds.

The soil under consideration was Hostun $\mathrm{HN} 31$ sand $\left(\mathrm{d}_{10}=0.315 \mathrm{~mm}, \mathrm{~d}_{50}=0.480 \mathrm{~mm}, \mathrm{U}_{\mathrm{c}}=\right.$ 1.67, $\mathrm{e}_{\min }=0.555, \mathrm{e}_{\max }=1.01, \mathrm{G}_{\mathrm{s}}=2.65$ and air entry value, $\mathrm{AEV}$ of $1.3 \mathrm{kPa}$ ). The soil profiles that were tested in this study consisted of homogenous Hostun sand layers prepared at a relative density of about $40 \%$, using air pluviation technique and an automatic sand pourer described in [21]. For the application of air injection in the partially saturated models, a rubber air curtain hose, with several tiny openings of about $0.5 \mathrm{~mm}$ diameter and $5 \mathrm{~mm}$ spacing, was placed on the centre-bottom of the model container. The sand was dry pluviated to attain $240 \mathrm{~mm}$ deep sand deposits, representing $16.8 \mathrm{~m}$ soil layers in prototype scale. During the model preparation, arrays of miniature pore pressure transducers (PPTs), piezoelectric and micro-electromechanical system (MEMS) accelerometers were positioned at the desired locations. Linear variable differential transducers (LVDTs) were also used to measure the settlements at different locations. Apart from the free-field centrifuge tests, the foundation was placed on the soil surface in each test. The schematic cross-section of the models is shown in Fig. 1.

In dynamic centrifuge modelling, adjusting the viscosity of the pore fluid by the same value as the gravity level is an accepted procedure to avoid the incompatibility between the dynamic and diffusion time scaling laws [23]. For this purpose, a high viscosity aqueous solution of hydroxypropyl methylcellulose (HPMC) was prepared with a viscosity of $70 \mathrm{cSt}$. The dry sand models were saturated very slowly with the viscous fluid and using the CAMSat system, as described by Stringer and Madabhushi [24]. The conventional mass and volume method was used to determine the degrees of saturation of models. The computed 
degrees of saturation at the end of the saturation process were consistently above $99 \%$. It is worth noting that the masses, volumes and densities of the pore fluid and solids were determined very carefully. However, certain errors were still expected to happen in the computed saturation ratios due to the sensitivity of the conventional method [25]. The phreatic surface of the saturated models was approximately $0.35 \mathrm{~m}$ above the ground surface after spinning.

A stored angular momentum (SAM) actuator device [26] was used to generate sinusoidal pseudo-harmonic input motions. The shakings were parallel to the long side of models. Peak base acceleration of around $0.18 \mathrm{~g}$ was used for the tests.

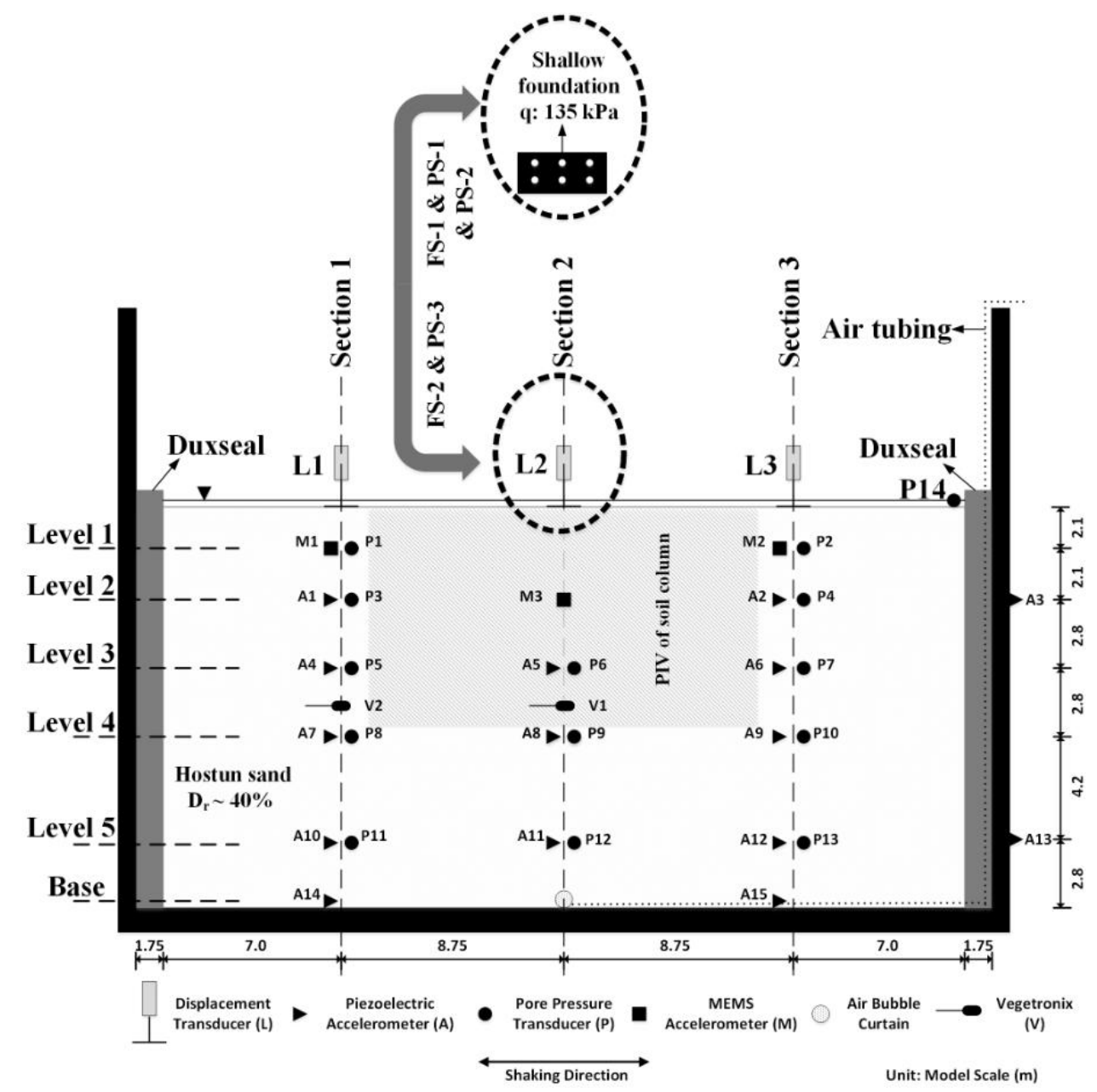

Fig. 1. Cross-section of the centrifuge models with and without shallow foundation. 


\subsection{Air injection process}

To prepare the partially saturated soils, air was injected into the saturated models at the centrifugal acceleration of $70 \mathrm{~g}$, prior to each earthquake. Fig. 2 presents typical pressuretime and foundation settlement-time histories recorded during this process in PS-1 and PS-2. It is evident that different approaches were taken in each case. In PS-1, air pressure was increased rapidly until air bubbles became apparent on the ground surface. This resulted in a foundation settlement of $2.57 \mathrm{~mm}$ in model scale (180 $\mathrm{mm}$ in prototype), which would not be acceptable if this technique was applied to a field structure. In PS-2, a different approach was taken in which air injection pressure was increased gradually, and the response of foundation was monitored very carefully. As seen, the maximum air injection pressure was comparatively lower. The air-induced foundation settlement was only $0.2 \mathrm{~mm}$ in model scale (14 $\mathrm{mm}$ in prototype), which was quite smaller and tolerable.
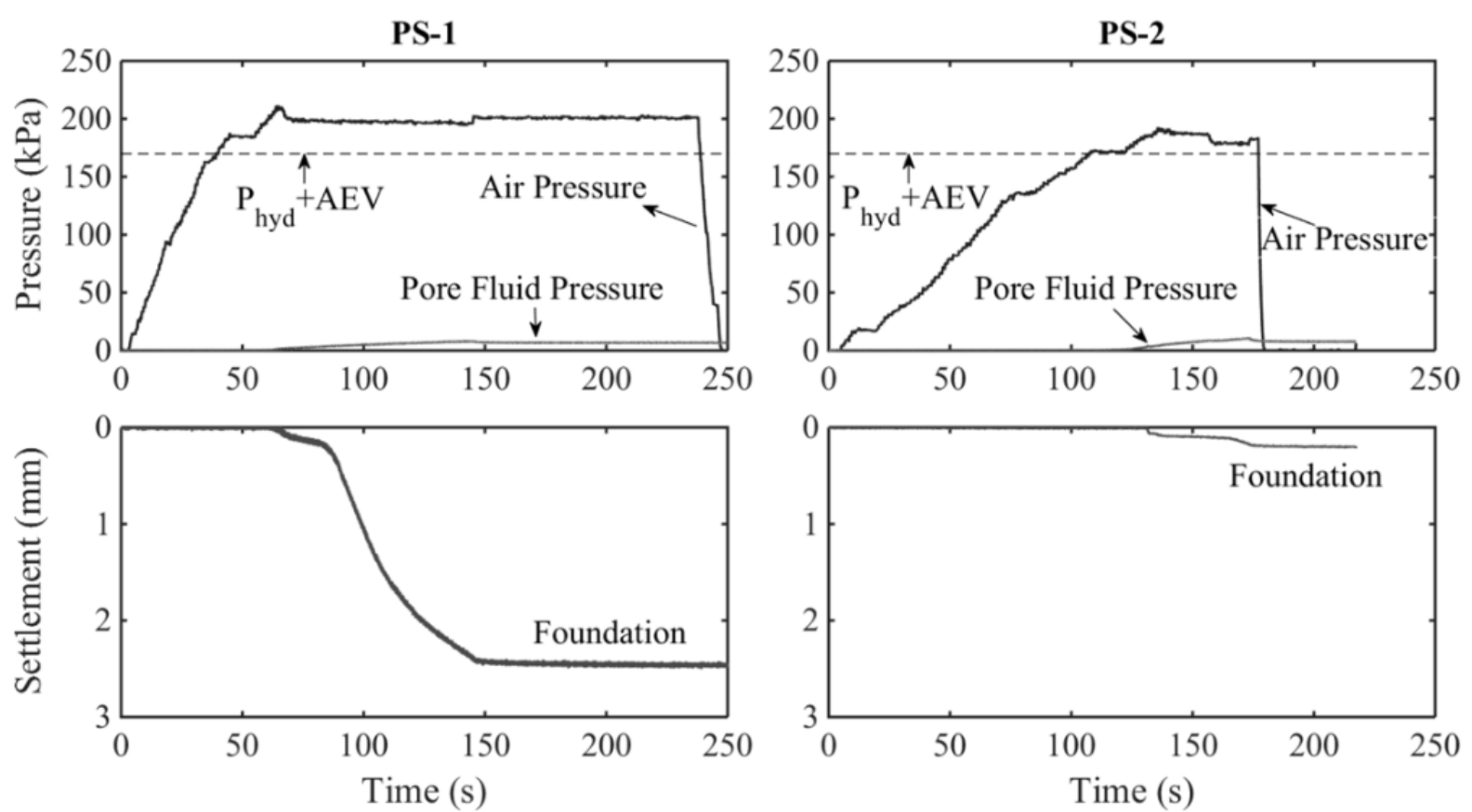

Fig. 2. Typical pressure-time and settlement-time histories during the air injection process (model scale).

In both cases, air began to enter the saturated granular medium when the air pressure reached the sum of hydrostatic pressure at the injection point and air entry value of soil. The ground water level rose due to the volume of pore fluid replaced by the volume of air that entered into the soil. The change in the water level thus pressure was captured by the pore pressure transducer (P14). Air injection was halted after approximately 200s (PS-1) and 60s (PS-2) in 
model scale once the air started to flow in the models. The pore pressures reduced to residual values. The decrease in the water level was primarily due to the excess/free air that escaped to the atmosphere. Final saturation ratio of soils was determined based on the volume of residual air bubbles retained in the soil pores in occluded form. The average residual degrees of saturation across the soil deposits were $89 \%$ and $86 \%$ in PS-1 and PS-2, respectively.

From these results, it can be suggested that the desaturation of soils beneath existing foundations requires a well-controlled air injection process and close monitoring of foundation response. Zeybek and Madabhushi [27] provides further experimental data for the effective application of air injection beneath existing foundations.

It was observed that injection of air into saturated soils changes the colour of soils. 2D digital images and digital videos taken before, during and after air injection showed that the colour of air-entrapped zones was much brighter than that of saturated zones in the front window. The images were processed with the image processing toolbox-MATLAB. Fig. 3 demonstrates the distribution of retained air bubbles in the partially saturated soil models, approximately determined based on the colour change. The approximate zone of influence is indicated by the broken curves. The area that can be monitored by the camera did not cover the whole soil model. Therefore, the actual position of the air injector is shown below the images in the figure. It is evident that before the air injection the colour of saturated soils was dark in PS-1(b) and PS-2(b). However, some brighter coloured soils became apparent right after the air injection in PS-1(a) and PS-2(a). The shape of air-entrapped zones was an almost $\mathrm{U}$ or $\mathrm{V}$, engulfing the majority of the instruments placed. It was almost symmetrical in PS-1, while it was less symmetrical in PS-2. It was observed that the colour of soil varied within the zone of influence in PS-2, showing that the uniformity of the desaturation was relatively less near the left edge of the foundation. Further experimental evidence regarding this phenomenon is given, using the results of the tests with comparatively lighter shallow foundation [27]. It is important to note that air bubbles were clearly identifiable as the shiny particles reflecting two LED lights. The bottom of the air-entrapped zones in the digital images was comparatively darker than the top side. This was attributed to the distance to the lights. Therefore, relatively darker colour of air-entrapped zones at the bottom in Fig. 3 should not be confused with the non-uniformity of desaturation near the left edge of the foundation in PS-2. 


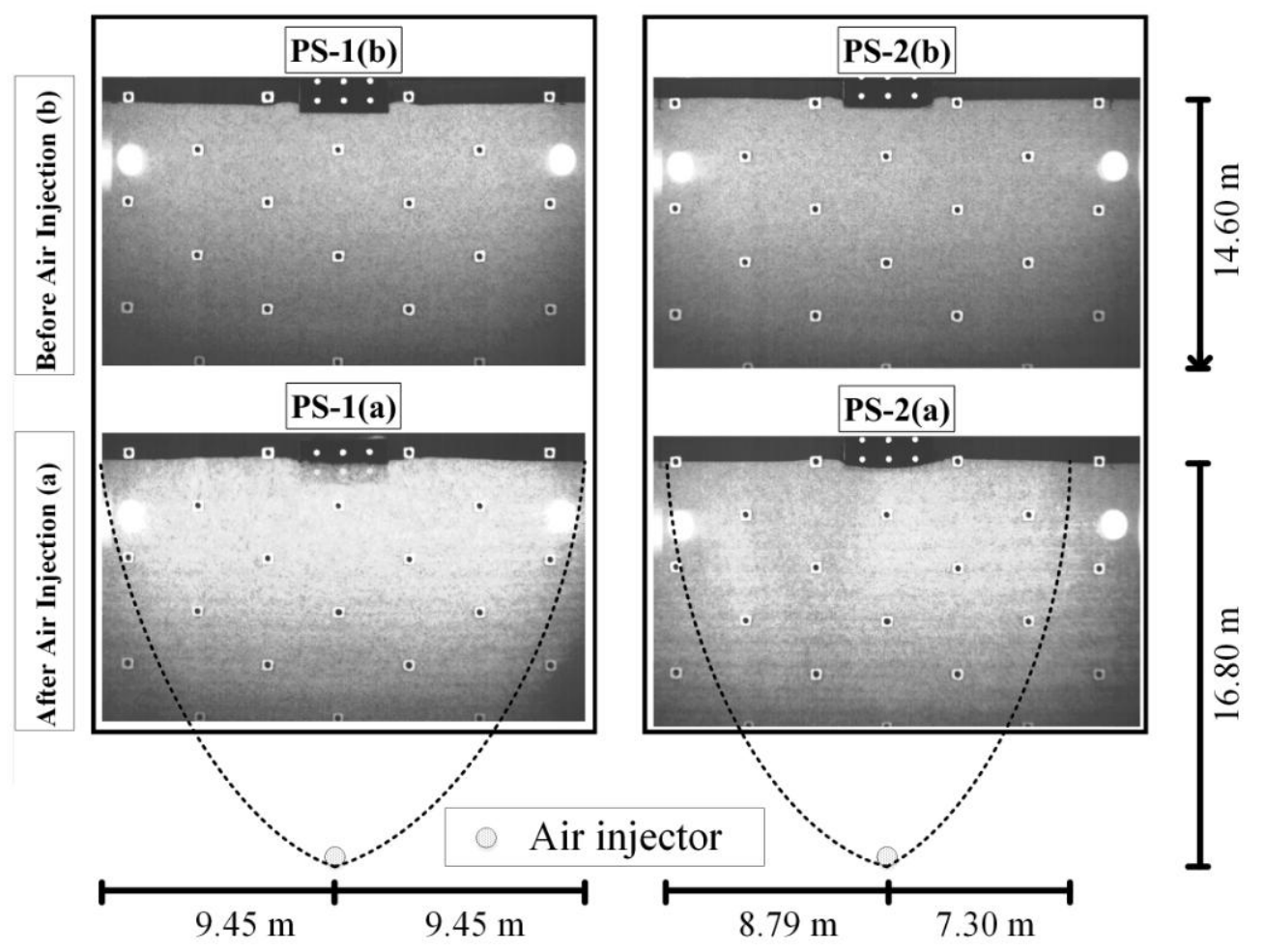

Fig. 3. Approximate desaturated zones (Brighter colours are indicative of retained air bubbles).

\subsection{Image analysis}

The soil deformations beneath the shallow foundations were achieved using particle image velocimetry (PIV) technique. The analysis method and further details about the Geo-PIV software were given by White et al. [28]. Digital images were obtained using a high speed camera which has a resolution of 3 mega-pixel and a storage capacity of 1000 full resolution images. A typical test setup for the tests, showing the high speed camera and two LED lights fixed in front of the Perspex window, is presented in Fig. 4. The images were processed, and the corresponding displacements during air injection and earthquakes were obtained in image space (pixels). These displacements were then converted to physical units ( $\mathrm{mm}$ ) using a series of black control markers at precisely known positions on the Perspex window. 

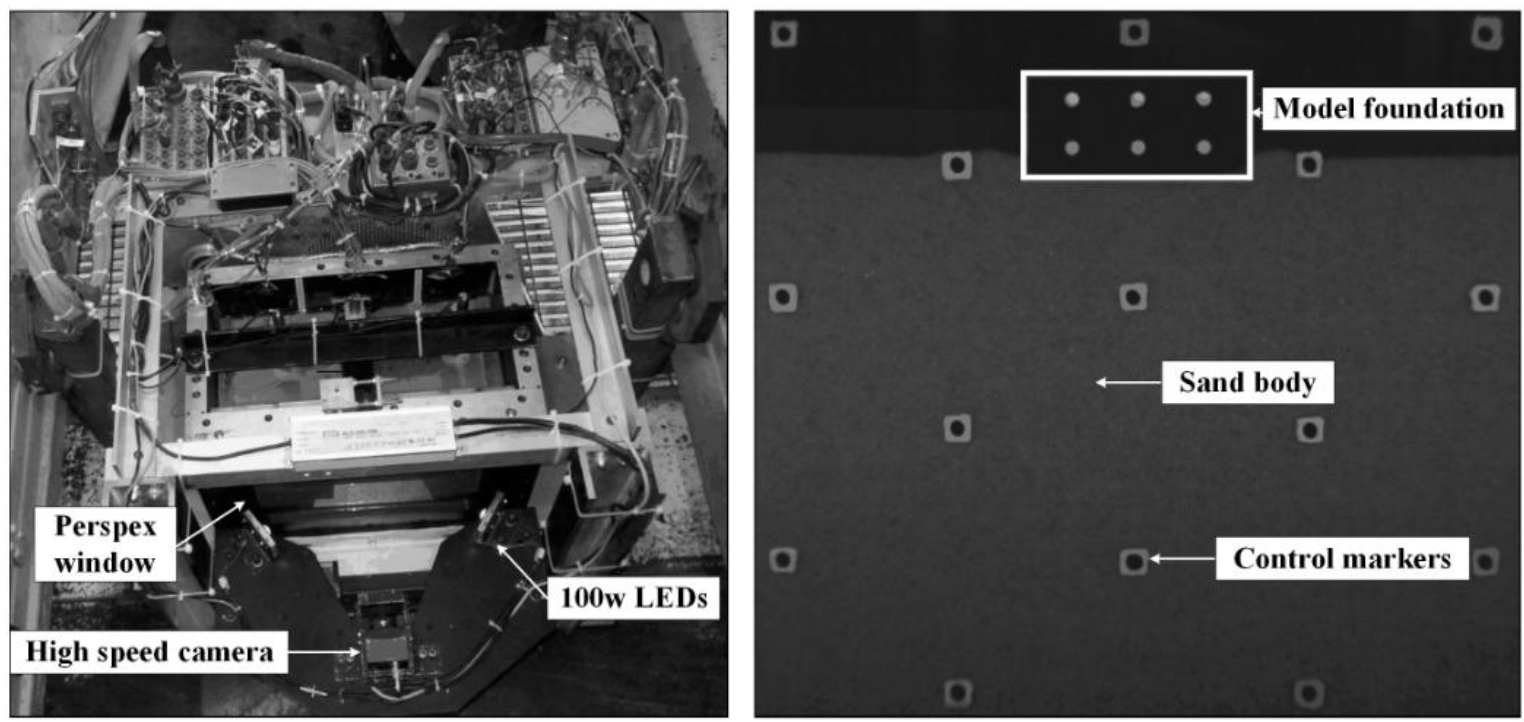

Fig. 4. Setup for digital imaging in centrifuge tests (left) and an example image (right).

\section{Centrifuge test results and discussions}

In an effort to offer insights into the impacts of air injection particularly on the seismic response of soils, the settlement-time histories in combination with the excess pore pressure distributions across the soil deposits are presented. The variation of shear stiffness with air injection is also evaluated. In order to identify the dominant settlement-generating mechanisms in the saturated and partially saturated soils, displacement vectors fields developed in the free-field and beneath shallow foundations are depicted. The presented results in fact represent only a small portion of the analyses carried out, but are representative of the larger dataset.

\subsection{Soil response and displacement mechanisms in the free-field}

Fig. 5 presents typical time histories of settlements, excess pore pressures and input acceleration recorded in the free-field tests. The presented results correspond to the test data attained from Section 1, as shown in the cross-section of Fig. 1. The time axis is split into four windows in different scales in order to separately investigate the co-seismic response in the initial and following cycles as well as the post-seismic response in the short-term and long-term, respectively. The settlement that occurred during the air injection process in PS-3 is indicated by a horizontal dashed line in the first time window of the topmost figure. The excess pore pressures are those recorded at two different depths of soil deposits. The initial 
liquefaction at which the excess pore pressure, $\Delta_{u}$ generated during the earthquake is equal to the initial (pre-earthquake) vertical effective stress, $\sigma_{v 0}^{\prime}$ at the corresponding soil layer (excess pore pressure ratio, $r_{u}=\frac{\Delta_{u}}{\sigma_{v 0}^{\prime}}=1$ ) is shown as the horizontal dashed line in the same figure.

It is apparent that a very different response was observed for the saturated soil (FS-2) and partially saturated soil (PS-3). The reduction in the degree of saturation of soil substantially influenced the rate and extent of soil softening as well as timing of liquefaction and excess pore pressure dissipation. Excess pore pressures generated within each soil deposit touched the $r_{u}=1$ line, leading to significant strength loss at Level 1. Although the initial liquefaction was not reached in any case under the higher confining stress at Level 4, relatively greater excess pore pressure developed within the saturated soil as compared to its counterpart. This indicates that the extend of soil softening at this layer was relatively larger in the saturated case. While both soil deposits displayed a very similar initial rate of excess pore pressure build up at the shallow layer, excess pore pressure generation was observed to slow down at the deeper layer for the partially saturated soil. Once the earthquake ceased, the dissipation of excess pore pressures started from the base and propagated towards the ground surface. The shallow soil layer remained liquefied for longer, retaining the elevated excess pore pressures. This trend was observable for both cases. Nevertheless, the generated excess pore pressures started to drop relatively much faster in the partially saturated soil, revealing its different dissipation time response.

In the free-field tests, co-seismic ground surface settlements took place in each of the two soil deposits, with a slightly decreasing rate towards the end of earthquakes. The rate of coseismic and post-seismic ground surface settlements was much greater in the case of saturated soil, resulting in larger total surface settlement. In particular, the contribution of post-seismic surface settlements, due to re-consolidation associated with the dissipation of excess pore pressures, was relatively major in the saturated case in comparison with its partially saturated counterpart. The increased rate of co-seismic settlement in the saturated soil can be ascribed to the partial drainage which allows pore fluid flow during shaking [29]. Since the generation of excess pore pressure gradients and loss in the shear stiffness (see Fig. 7) were comparatively limited in the partially saturated soil, a decreasing trend in the postseismic settlement was observed. The surface settlement predominantly stemmed from the 
increased compressibility of soil matrix due to air bubbles reducing in volume during dynamic loading.

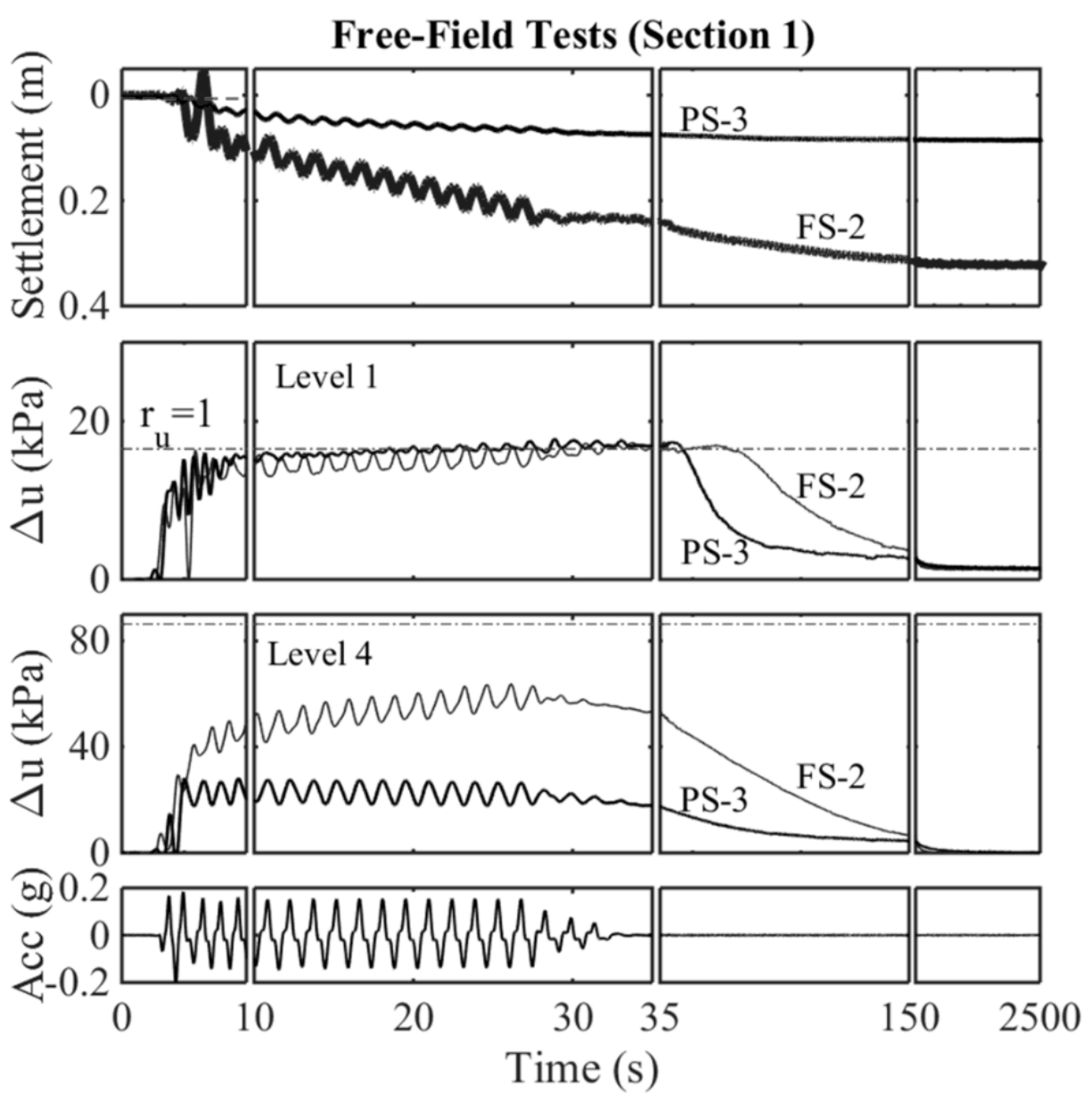

Fig. 5. Typical settlement, excess pore pressure and input motion time histories recorded in the free-field tests.

While the time histories presented in Fig. 5 shed light on the qualitative evaluation of the deformation mechanisms that contributed the surface settlement of saturated and partially saturated soils, the displacement field vectors can offer an opportunity for the quantitative assessment of the prevailing deformation mechanisms in such soils. For this purpose, the horizontal, vertical and total soil displacement contours accumulated over the whole duration of seismic motions in the free-field tests are shown in Fig. 6. The displacements were calculated relative to the rigid base and using PIV within the soil zone that could be captured by the camera, as shown in the cross-section of Fig. 1. It is apparent that the saturated soil (FS-2) displayed an asymmetric horizontal and total displacement mechanism. The soil had a tendency to laterally displace outwards, and the largest horizontal and total displacements were observed at the left hand side of the model ground. The lateral displacement of soil is 
suggestive of deviatoric type of deformation in the saturated soil due to earthquake-induced shear stresses. In addition, a depth of approximately $4 \mathrm{~m}$ soil moved vertically downwards. However, the displacement contours recorded for the partially saturated soil (PS-3) revealed that the magnitude and shape of the displacement contours profoundly changed with the injection of air. They were relatively symmetrical in shape. The laterally outward soil movements reduced significantly, indicating that deviatoric type of shear deformations were limited. Localised areas of high displacement magnitude were observable only at the shallower locations.
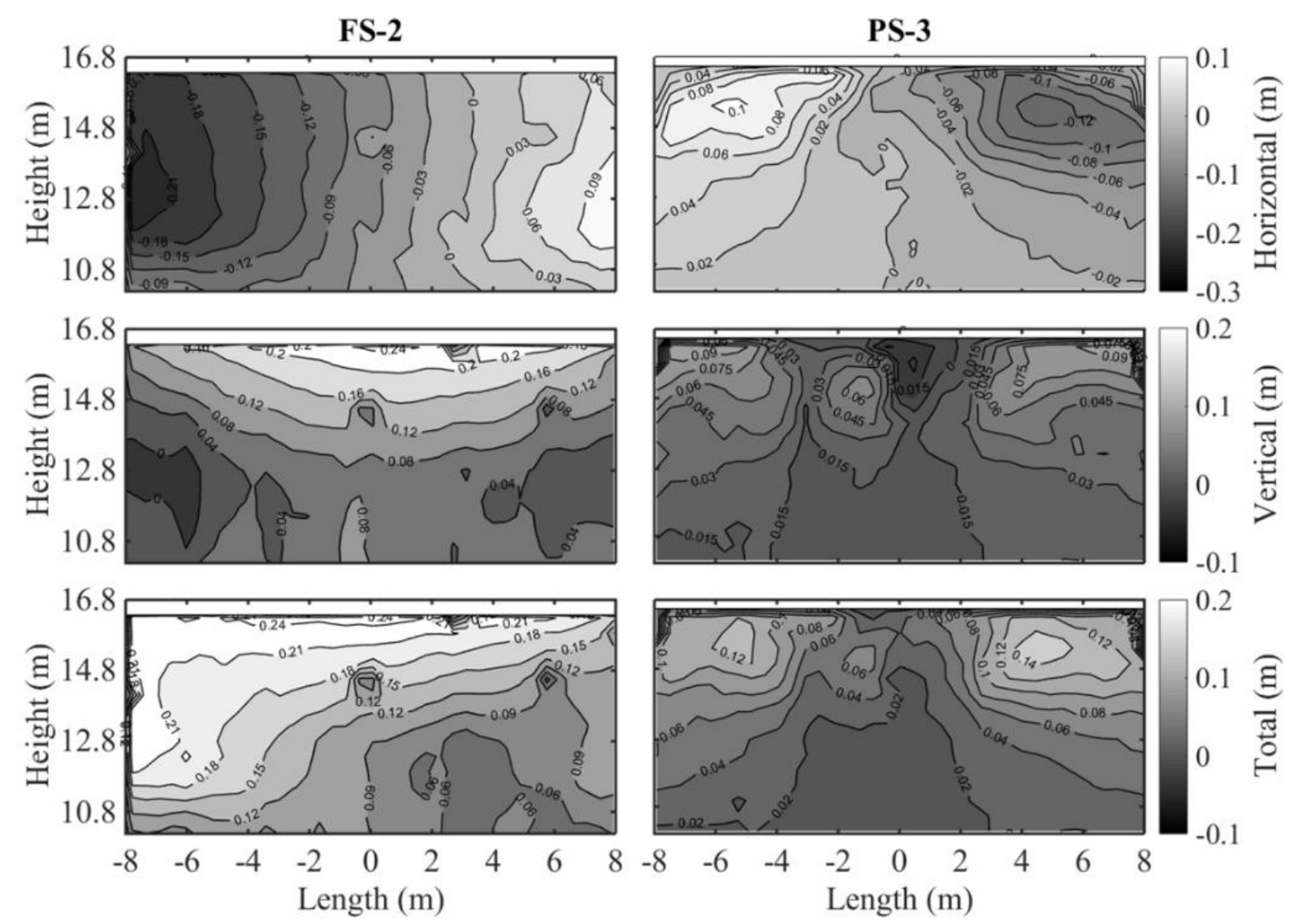

Fig. 6. Contours of horizontal, vertical and total displacement at the end of the earthquake in the free-field tests.

The dynamic shear stress-strain response of soils was calculated to examine how air injection affects the shear stiffness of soils. Fig. 7 presents typical excess pore pressure, input acceleration, shear stress \& strain time histories along with the shear stress-strain loops recorded in Section 1 and at Level 2 for FS-1 and PS-2. The shear stresses and strains were calculated using the vertical array of acceleration data recorded at different soil layers and following the methodology proposed by Elgamal et al. [30]. A one-dimensional vertical shear 
wave propagation within the soil columns was assumed. It is seen that during the first two cycles of the earthquake excess pore pressure generated, and saturated soil layer (FS-1) liquefied. It experienced larger shear strains and smaller shear stresses, showing a softened shear stress-strain $(\tau-\gamma)$ loop. Nevertheless, the partially saturated soil at the equivalent soil layer experienced relatively smaller shear strains and larger shear stresses during the pore pressure build-up, which is suggestive of a stiffer response. The drop in the shear stiffness of soil was very limited in this case.
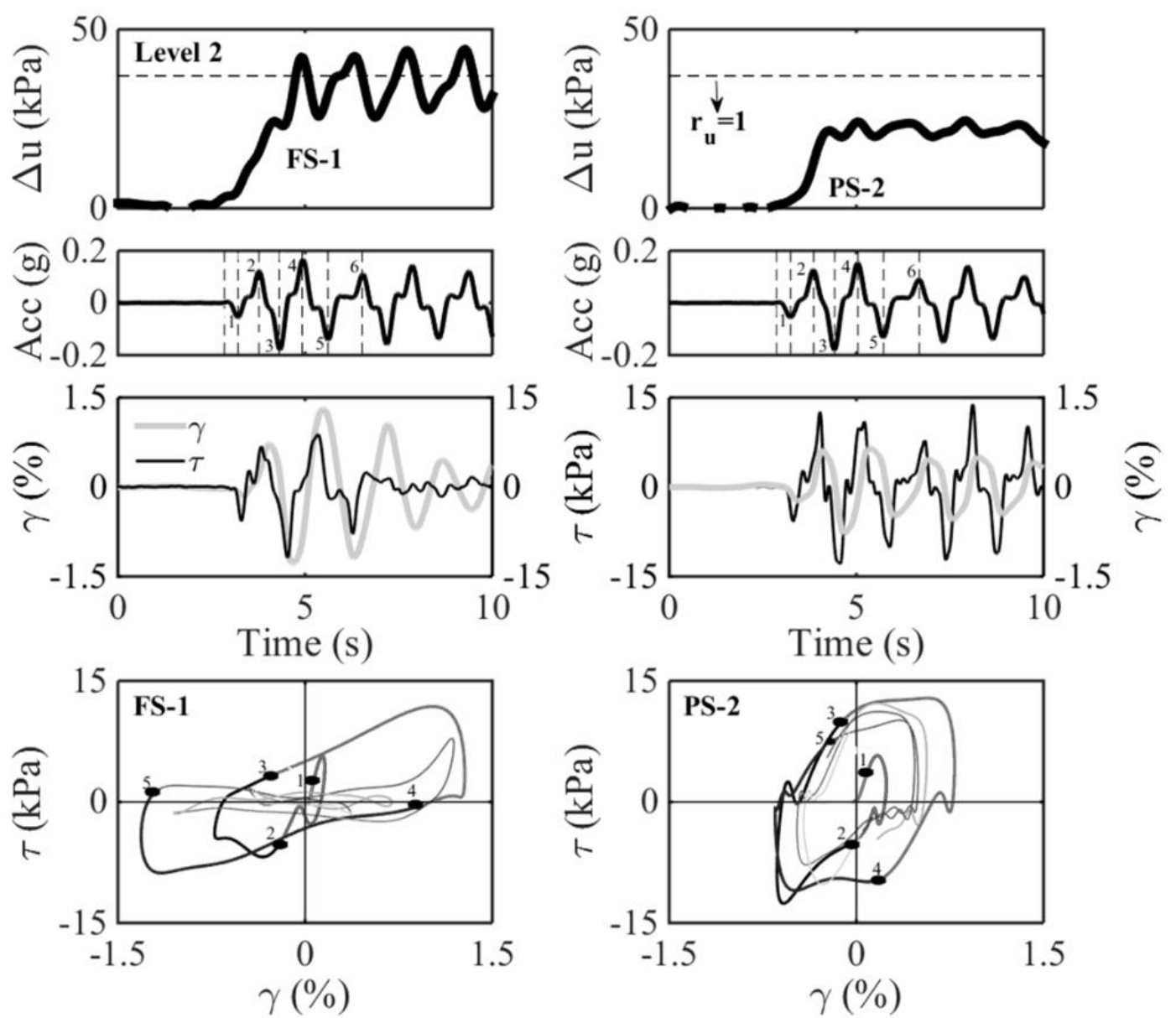

Fig. 7. Excess pore pressure, input acceleration and shear stress \& strain time histories along with the shear stress-strain loops recorded in Section 1 for FS-1 (left) and PS-2 (right).

\subsection{Air-induced displacement mechanisms beneath shallow foundations}

The injection of air can cause permeant settlement of shallow foundations, as reported in section 2.2. Despite its small magnitude, air-induced settlement might be still a major concern of the practising engineers. In an effort to gain insight into the settlement-generating mechanisms taking place during the air injection process, PIV analyses were performed. Fig. 
8 demonstrates the typical air-induced displacements that developed beneath the shallow foundations and in the free-field for PS-1 and PS-2. It is apparent that air injection resulted in vertically downward displacements in the free-field, which was the case particularly for PS-2. Air injection also caused the foundation soil to displace laterally towards the free-field for both cases. It is worth noting that air-induced soil displacements were barely visible on the left side of the foundation in PS-2 due to relatively more heterogeneous air-entrapped zones in this test.

As indicated earlier, the replacement of pore fluid within the voids of soil by occluded air bubbles occurred during the air injection process. This led to an upward migration of pore fluid within the soil deposits. When this process occurred rapidly (such as in PS-1), effective stresses in the upper part of soil layers with low confining stresses dropped significantly, and flow-induced liquefaction took place at these locations. Moreover, the compressibility of soil matrix was expected to increase with the inclusion of air bubbles. The downward soil displacements in the free-field are therefore attributed to the positive volumetric strains caused by the decrease in the effective stresses during the air injection and increased compressibility of soil matrix. These volumetric strains caused the free-field settlements, while the foundation imposed static shear stresses caused an almost complete (PS-1) or partial \& localised (PS-2) bearing capacity deformations. They eventually led to the settlement and rotation of the foundations. However, since the recorded air-induced settlements and rotations were significantly smaller in PS-2, they were not expected to have significant effect on the seismic response of foundation.

The observations made during the partially saturated soil experiments revealed that small amount of retained air bubbles had a tendency to coagulate during the air injection process, forming temporary and localised air-filled cavities. Moreover, after the air injection ceased the excessive air bubbles, moving upwards, slightly pushed the upper soil particles at the very top where the confining stresses are very small. These eventually led to volumetric expansion in these regions. Nevertheless, the volumetric strains associated with the increased soil compressibility surpassed the localised volumetric expansion in these soils. 


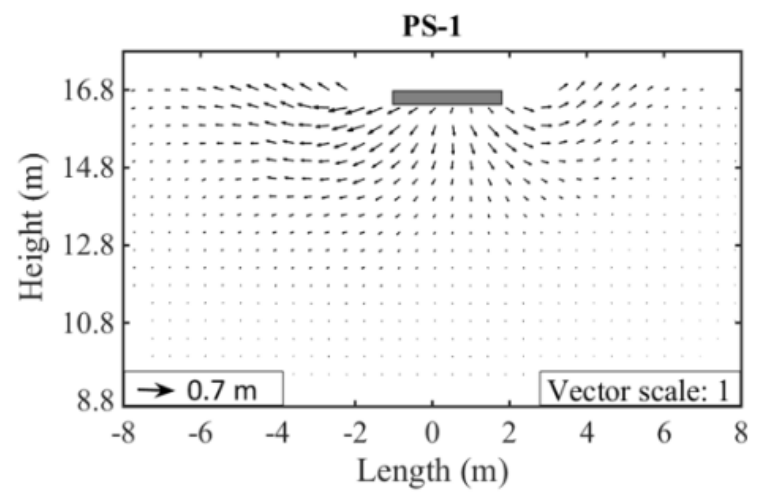

Horizontal Displacement (m) Vertical Displacement (m)

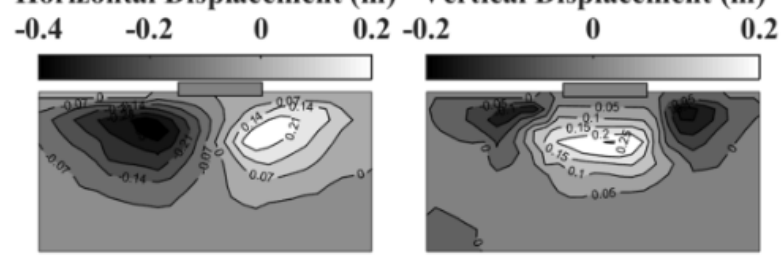

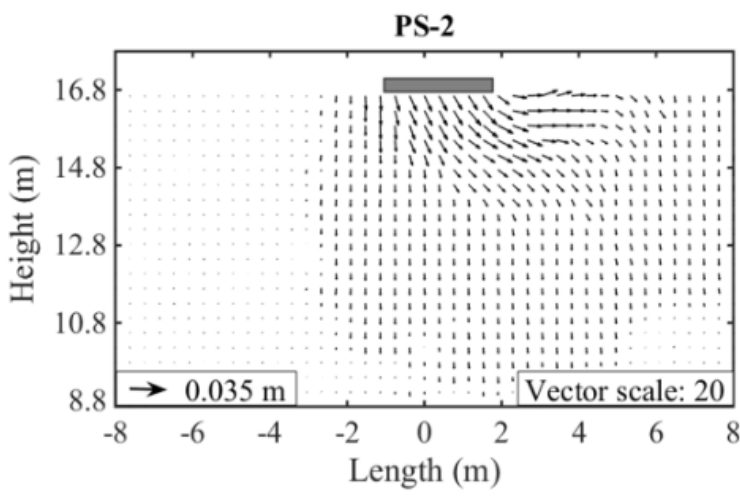

Horizontal Displacement (m) Vertical Displacement (m)

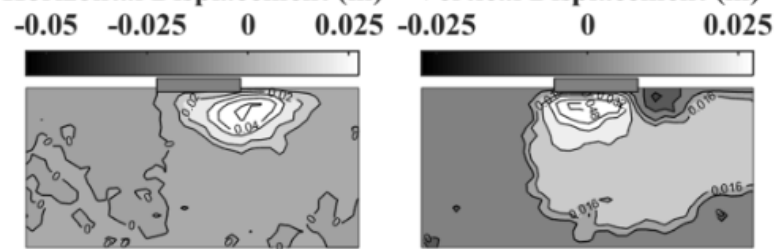

Fig. 8. Displacement vectors, contours of horizontal and vertical displacement recorded during the air injection.

\subsection{Soil response and displacement mechanisms beneath shallow foundations}

Fig. 9 shows the variation of excess pore pressure ratios $\left(r_{u}\right)$ within the soil models, calculated based on the peak values of excess pore pressures generated during the earthquakes. It must be highlighted that foundation-induced stresses were accounted for while computing the initial vertical effective stresses at the corresponding soil layers. In addition, since the excess pore pressure ratio contours could only be drawn at the locations of pore pressure transducers (PPTs), an interpolation was of necessity for the rest of the soil layers. It seems that air injection significantly minimised the excess pore pressure generation. At the equivalent soil layers, generally much smaller $r_{u}$ values were observed in the partially saturated soils (PS-1 and PS-2), in comparison to their saturated counterpart (FS-1). Nevertheless, the influence of air injection on the soil's resistance to pore pressure generation appeared to decrease at shallow layers with low confining stresses (usually $2.1 \mathrm{~m}$ ) and at locations away from the air injector, signifying the importance of confining stress for the liquefaction resistance of partially saturated soils [8] and the extent of air-entrapped zone [31]. 


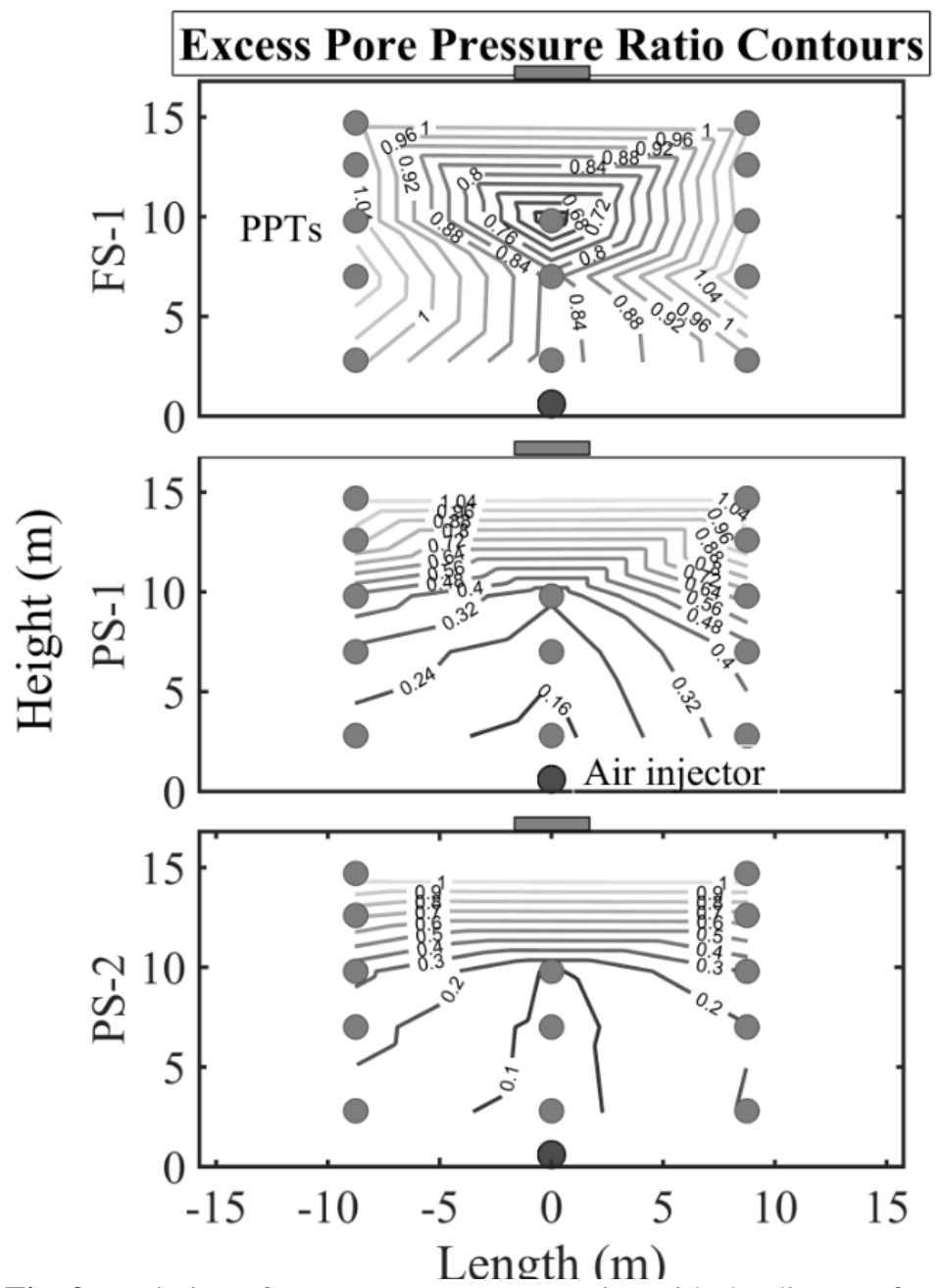

Fig. 9. Variation of excess pore pressure ratios with the distance from the air injector and with soil depth.

The ground surface displacement (Section 1 and Section 3) and foundation displacement (Section 2) along with the recorded acceleration time histories are plotted for FS-1 and PS-2 in Fig. 10. The positive displacement in this figure indicates the vertically downward settlement, whereas the negative displacement represents the heave. It is apparent that in the saturated soil (FS-1) the foundation settled significantly during the earthquake, with a settlement rate of almost linear with time. An upward movement of soil surface was observed at the locations of Section 1 and Section 3. Once the earthquake ceased, the soil surface at the corresponding locations started to move downwards as the liquefied soil reconsolidated. Nevertheless, in the partially saturated soil (PS-2) the settlement of foundation reduced substantially, with a significantly smaller rate of co-seismic settlement. The surface of the soil at the locations of Section 1 and Section 3 moved only downwards. The foundation settlement was found to be only slightly larger than the settlements recorded in these locations and near the perimeter of the foundation. 

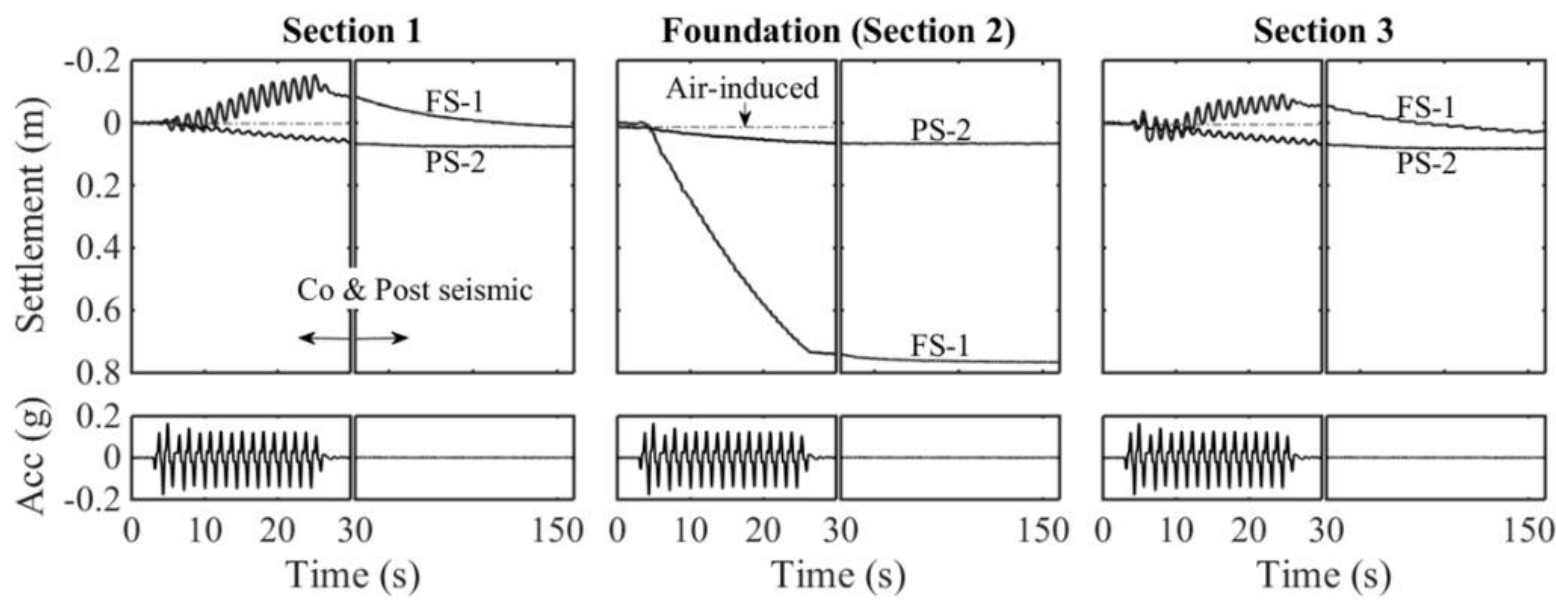

Fig. 10. Time histories of ground surface \& foundation displacement and input acceleration for FS-1 and PS-2.

Fig. 11 presents the horizontal, vertical and total displacement contours corresponding to the full cycles of seismic motion in FS-1 and PS-2. The location of the foundation after the end of the earthquakes was roughly indicated in the figure. It appears that a symmetric displacement mechanism occurred in the saturated soil (FS-1). Significant deformations were evident beneath and under both edges of the foundation. There was a wedge of soil that moved almost as a block vertically downwards underneath the foundation. Moreover, a large extent of liquefied soil adjacent to the foundation moved downwards, following the settlement of the foundation. The inability of the liquefied free-field soil to provide lateral confinement caused the rest of the liquefied soil layer to be displaced laterally and pushed outwards, causing the surface of the soil to heave at the locations of Section 1 and Section 3 as shown in Fig. 10. It is worth noting that the area monitored by the camera did not engulf the entire soil zones, as demonstrated in the cross-section of the models in Fig. 1. However, it can be said that the upward movement of soil towards the edges of the model container might have been facilitated by its boundaries due to the large extent of the displacement mechanism observed in this test. In the saturated soil, the depth of liquefaction increased to a level where a bearing capacity failure mechanism formed. Relatively larger vertically downward displacements around the edges of the foundation can suggest that the positive volumetric strains at locations away from the foundation were surpassed by the deviatoric strains, causing the foundation to settle more than those locations. This correlated well with the observations of several researchers [29-32].

In the partially saturated soil (PS-2), the displacement mechanisms were relatively more localised, and mobilisation of a bearing capacity failure mechanism was not the case. The 
magnitude of total soil displacement was significantly smaller, and the majority of soil deformations occurred vertically downwards, with little lateral movement of foundation soil into the free-field. This indicates that air injection provided lateral confinement for the foundation soil, and limited the deviatoric type of deformations. Nevertheless, vertical soil displacements due to the positive volumetric strains associated with the increased compressibility of soil matrix seemed to contribute significantly to the total settlements. There was a lack of symmetry in PS-2 in which no lateral soil movements were visible at the right hand side of the foundation, but only vertically downward displacements were present. The asymmetric deformation mechanism in this soil can be attributed to the asymmetry in the earthquake loading and non-uniform partial saturation within the soil column (see Fig. 3).
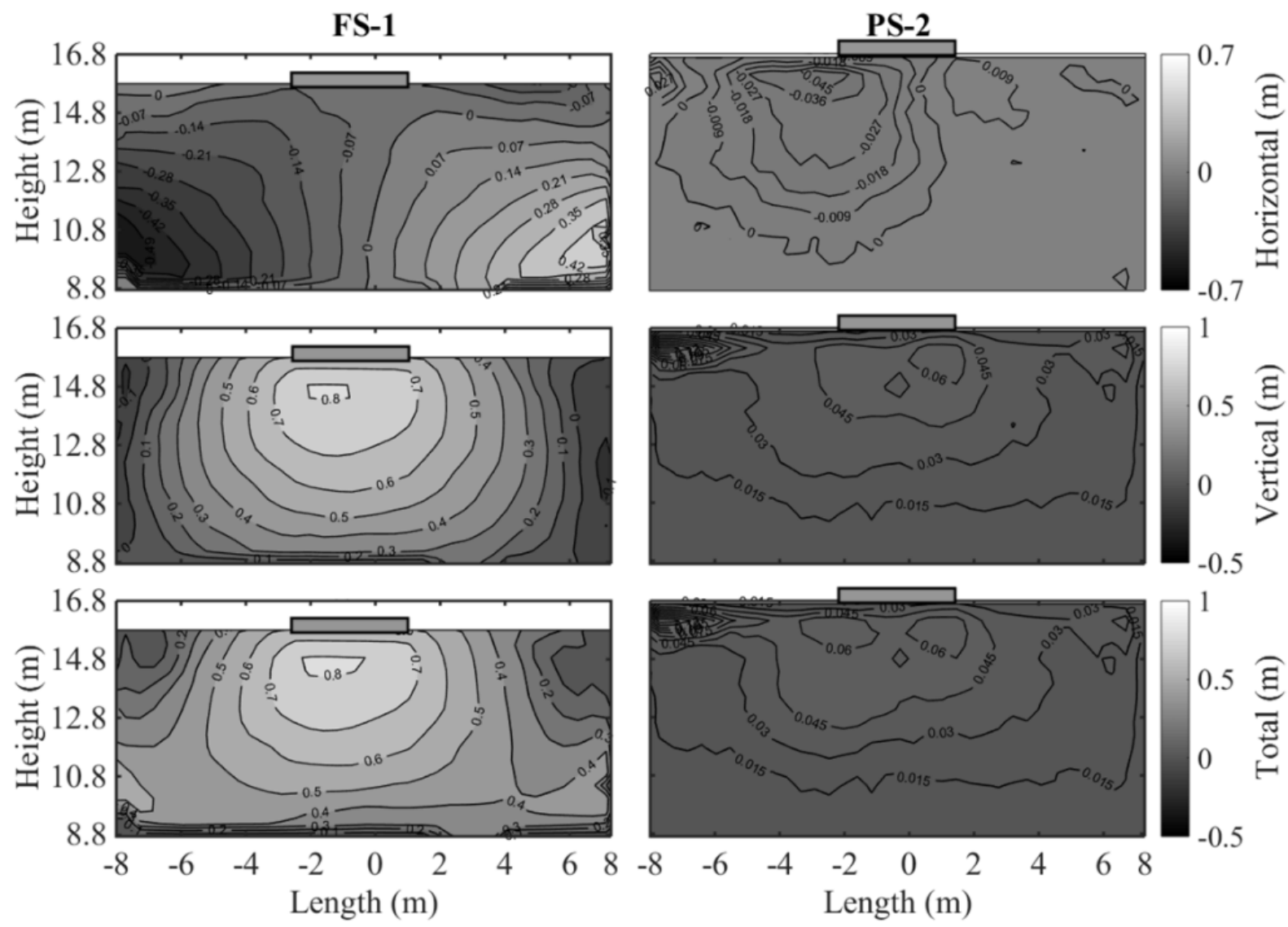

Fig. 11. Contours of horizontal, vertical and total soil displacement developed beneath the shallow foundations, corresponding to the whole duration of earthquakes.

Examination of the soil displacements on a cycle-by-cycle basis can provide a much clearer view of the size, shape and changes in the deformation mechanisms that affect the soil layers. For this purpose, the soil displacement vectors occurring during half-cycles near the 
beginning of earthquakes were examined for the tests, and typical results are presented in Fig. 12. Indicated on the lowest two traces are the approximate time period for which the displacements were examined. The left column of the figure shows the displacements that occurred in the saturated soil (FS-1) during each half-cycle, commencing from a point when the foundation started to settle significantly. A pattern of almost linear and very large foundation settlement rate was recorded by LVDT-L2, particularly after the half-cycle (2-3). The same pattern was ascertained from PIV-obtained displacement. Significant deformation occurred during each half-cycle, and the depth of the deformation increased up to more than twice of foundation width (7.7 $\mathrm{m}$ in prototype scale), specifically from phase 3-4 to 5-6. As discussed in Fig. 11, the deformation wedges moving almost as a whole were apparent, and the size of the deformation zone increased in its lateral extent due to the fully liquefied freefield soil that fell short of lateral support. One-sided deformation wedge to the right or left of the foundation took place depending on the direction of the box movement, and these movements were accompanied by the vertical settlement of foundation. This points out that deformation occurred twice during each cycle of earthquake. The deviatoric strains that developed under the shear stresses induced by the foundation and earthquake can be easily observed, especially after phase 3-4. Although it is difficult to distinguish the deviatoric and volumetric strains from the overall displacements, it is clear that the accumulated deviatoric strains contributed significantly. This is evident from the large lateral deformation components in the soil layer.

The middle and left column in Fig. 12 demonstrate the soil displacements and foundation settlements occurring during each half-cycle in the partially saturated soils (PS-1 and PS-2). It appears that in both cases the rate of foundation settlement was significantly smaller compared to that recorded in their saturated counterpart. In PS-1, a rapid settlement of foundation during the first three half-cycles (from 2-3 to 4-5) was followed by a reduced rate of settlement during the last half-cycle (phase 5-6) and during the rest of the earthquake. Correspondingly, the magnitude of soil deformations was smaller and much shallower in this soil. In general, an overall movement of sand body from side to side at the very shallow layers was apparent. There was only a small size of soil wedge that moved down and away from the foundation under both edges of the foundation, which were indicative of smaller deviatoric strains. This was particularly the case for phase 2-3 and 3-4. A very similar trend was observable for PS-2. The magnitude of displacement vectors and the depth of 
deformation were the least in this soil. Although slight deviatoric strains under the foundations were apparent in phase 5-6, the soil displacements underneath the foundation were generally in downwards direction, and there was almost no horizontal soil movement under the foundation in phase 4-5.
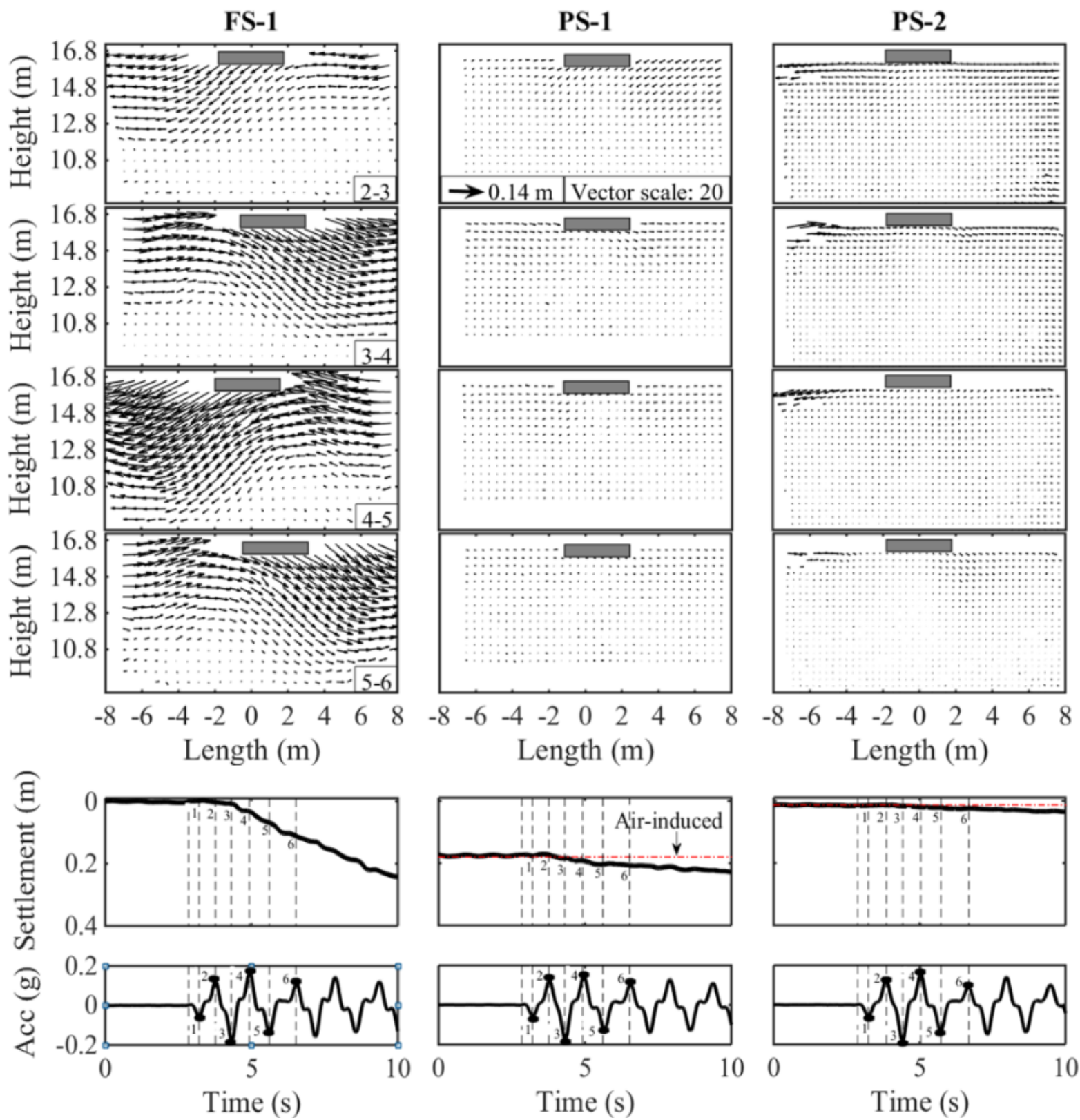

Fig. 12. Displacement vector fields beneath shallow foundations and foundation settlements during half-cycles near the beginning of earthquake. Vector length scale is 20 for all cases.

All in all, the most critical deformation mechanisms at play in the saturated and partially saturated soils were identified in this paper. In the saturated soil, the volumetric strains due to partial drainage during seismic loading and most importantly deviatoric strains due to 
earthquake-induced shear stresses resulted in large ground surface settlements. Although the majority of the free-field settlements seemed to happen during seismic events, post-seismic reconsolidation displacements also contributed to the total settlements at the soil surface. In fact, these observations are in accordance with the results of recent centrifuge tests [29].

In a similar way, the mechanisms that seemed to control the settlement in the partially saturated soils were determined, and they are listed in Table 2. Although little deviatoricshear type of deformation was present, the prevailing settlement-producing mechanism was the volumetric type of deformation in these soils. As the degrees of saturation of soils reduced with air injection, the increased compressibility of the soil matrix appeared to contribute considerably to the total soil settlements during earthquakes. The contribution of post-seismic displacements to the overall surface settlements remained insignificant in this case.

Table 2 Mechanisms of deformations in the partially saturated soils.

\begin{tabular}{lll}
\hline During air injection & During and after earthquake \\
\cline { 2 - 4 } Volumetric & $\begin{array}{l}\text { Positive volumetric strains due to the } \\
\text { decrease in effective stress induced by } \\
\text { upward flow and due to the increase in the } \\
\text { compressibility of soil matrix }\end{array}$ & $\begin{array}{l}\text { Positive volumetric strains due to the } \\
\text { increase in the compressibility of soil }\end{array}$ \\
$\begin{array}{l}\text { Negative volumetric strains (expansion) } \\
\text { due to the coagulation of air bubbles } \\
\text { and upward air escape }\end{array}$ & $\begin{array}{l}\text { Limited volumetric strains due to the } \\
\text { consolidation during the excess pore } \\
\text { pressures dissipation }\end{array}$ \\
$\begin{array}{l}\text { Localised and partial bearing failure due } \\
\text { to the strength loss in the foundation soil } \\
\text { during upward flow }\end{array}$ & $\begin{array}{l}\text { Limited bearing capacity failure } \\
\text { Leviatoric }\end{array}$ & $\begin{array}{l}\text { Limited cumulative foundation } \\
\text { settlements due to shear deformation }\end{array}$ \\
\hline
\end{tabular}




\section{Conclusions}

This paper investigated the efficacy of air injection to remediate liquefaction in the free-field and beneath shallow foundations using dynamic centrifuge tests and PIV analysis. The main intent of the paper was to offer some novel insights into the influence of air injection on the deformation mechanisms that developed in the free-field and beneath shallow foundations.

The seismic response of liquefiable soil layers and shallow foundations resting on such deposits to air injection was studied. Based on the centrifuge test data, it was evident that air injection is a very effective technique to minimize the generation of excess pore pressures within the most of the soil layers and to reduce the liquefaction-induced foundation and ground surface settlements.

The most critical deformation mechanisms that actually prevailed in the saturated and partially saturated soils and their subsequent contributions to the overall foundation and ground surface settlements were identified in a novel way, using the displacement contours. It was seen that in the case of saturated soil the deviatoric and volumetric soil strains were both apparent, but the deviatoric strains seemed to dominate the settlement of shallow foundation. This was evident from the strong tendency of horizontal soil movements within the saturated soil layer and formation of an extended failure mechanism. The mass of soil beneath and around the edges of the foundation lost its lateral support from the surrounding soil which liquefied, and it accumulated vertical settlement with each half-cycle. Nevertheless, in the partially saturated soils the deviatoric type of deformations under the static and dynamic stresses were significantly minimized by the presence of air bubbles. The depth of liquefaction also markedly reduced, and a complete bearing failure mechanism under the shallow foundation did not form. In these soils, the volumetric deformation mechanism due to increased soil compressibility was found to be the primary cause of settlements.

\section{Acknowledgements}

The first author wishes to acknowledge the financial assistance provided during the course of this study by the Ministry of National Education (M.E.B.) of Turkey. The authors would also like to thank the technicians at the Schofield Centre of Cambridge University for their help during the experiments, and Dr. Mitsu Okamura for his guidance over the video call. 


\section{References}

[1] Bray, J., Sancio, R., Durgunoglu, T., Onalp, A., Youd, T., Stewart, J., Seed, R., Cetin, O., Bol, E., Baturay, M., Christensen, C., \& Karadayilar, T., (2004) "Subsurface Characterization at Ground Failure Sites in Adapazari, Turkey", Journal of Geotechnical and Geoenvironmental Engineering, ASCE, Vol. 130, No. 7, pp.673-685.

[2] Bertalot, D., Villalobos, F.A., \& Brennan, A.J., (2013) "Influence of Bearing Pressure on Liquefaction-Induced Settlement of Shallow Foundations", Géotechnique, Vol. 63, No. 5, pp.391-399.

[3] Yasuda, S., Harada, K., Ishikawa, K., \& Kanemaru, Y., (2012) "Characteristic of Liquefaction in Tokyo Bay Area by the 2011 Greatest Japan Earthquake", Soils and Foundations, Vol. 52, No. 5, pp.793-810.

[4] Seed, R. B., Cetin, K. O., Moss, R. E. S., Kammerer, A. M., Wu, J., Pestana, J. M., Riemer, M. F., Sancio, R. B., Bray, J. D., Kayen, R. E., \& Faris, A., (2003) "Recent Advances in Soil Liquefaction Engineering: A Unified and Consistent Framework", $26^{\text {th }}$ Annual ASCE Los Angeles Geotechnical Spring Seminar, Long Beach, CA, April 30.

[5] Tsukamoto, Y., Ishihara, K., Nakazawa, H., Kamada, K., \& Huang, Y., (2002) "Resistance of Partly Saturated Sand to Liquefaction with Reference to Longitudinal and Shear Wave Velocities", Soils and Foundations, Vol. 42, No. 6, pp.93-104.

[6] Mitchell, J. K., \& Santamarina, J. C., (2005) "Biological Considerations in Geotechnical Engineering”, Journal of Geotechnical Engineering, Vol. 131, No. 10, pp.1222-1233.

[7] Yoshimi, Y., Yanaka, K., \& Tokimatsu, K., (1989) "Liquefaction Resistance of a Partially Saturated Sand", Soils and Foundations, Vol. 29, No. 2, pp.157-162.

[8] Okamura, M., \& Soga, Y., (2006) "Effects of Pore Fluid Compressibility on Liquefaction Resistance of Partially Saturated Sand", Soils and Foundations, Vol. 46, No. 5, pp.695-700. 
[9] Yegian, M. K., Eseller-Bayat, E., Alshawabkeh, A., \& Ali, S., (2007) "Induced Partial Saturation (IPS) for Liquefaction Mitigation: Experimental Investigation", Journal of Geotechnical and Geoenvironmental Engineering, ASCE, Vol. 133, No. 4, pp.372-380.

[10] Takemura, J., Igarashi, R., Izawa, J., \& Okamura, M., (2008) "Centrifuge Model Tests on Soil Desaturation as a Liquefaction Countermeasure", Proceedings of the $5^{\text {th }}$ International Conference on Urban Earthquake Engineering, Tokyo Institute of Technology, Tokyo, Japan, pp.269-274.

[11] Eseller-Bayat, E., Yegian, M. K., Alshawabkeh, A., \& Gokyer, S., (2013) "Liquefaction Response of Partially Saturated Sands. I: Experimental Results" Journal of Geotechnical and Geoenvironmental Engineering, ASCE, Vol. 139, No. 6, pp.863-871.

[12] He, J., Chue, J., \& Ivanov, V., (2013) "Mitigation of Liquefaction of Saturated Sand Using Biogas", Géotechnique, Vol. 63, No. 4, pp.267-275.

[13] Tokimatsu, K., Yoshimi, Y., \& Ariizumi, K., (1990) "Evaluation of Liquefaction Resistance of Sand Improved by Deep Vibratory Compactions”, Soils and Foundations, Vol. 30, No. 3, pp.153-158.

[14] Okamura, M., Ishihara, M., \& Oshita, T., (2003) "Liquefaction Resistance of Sand Deposit Improved with Sand Compaction Piles", Soils and Foundations, Vol. 43, No. 5, pp.175-187.

[15] Okamura, M., Ishihara, M., \& Tamura, K., (2006) "Degree of Saturation and Liquefaction Resistances of Sand Improved with Sand Compaction Pile", Journal of Geotechnical and Geoenvironmental Engineering, ASCE, Vol. 132, No. 2, pp.258-264.

[16] Okamura, M., \& Tomida, Y., (2015) "Full Scale Test on Cost Effective Liquefaction Countermeasure for Highway Embankment", Proceedings of $6^{\text {th }}$ Internal Geotechnical Symposium on Disaster Mitigation in Special Geoenvironment Conditions, IIT Madras,

[17] Okamura, M., Tomida, Y., Okamoto, T. \& Yasuhara, H., (2012) "Remedial Measure for Highway Embankments on Liquefaction Prone Foundation", Proceedings of $2^{\text {nd }}$ International Conference on Performance-Based Design in Earthquake Geotechnical Engineering, Taormina, Italy, pp.615. 
[18] Marasini, N.P., \& Okamura, M., (2015) “Air Injection to Mitigate Liquefaction under Light Structures", International Journal of Physical Modelling in Geotechnics, Vol. 15, No. 3, pp.129-140.

[19] Marasini, N.P., \& Okamura, M., (2015) "Numerical Simulation of Centrifuge Tests to Evaluate the Performance of Desaturation by Air Injection on Liquefiable Foundation Soil of Light Structures”, Soils and Foundations, Vol. 55, No. 6, pp.1388-1399.

[20] Zeybek, A., \& Madabhushi, S.P.G., (2017) "Centrifuge Testing to Evaluate the Liquefaction Response of Air-Injected Partially Saturated Soils beneath Shallow Foundations", Bulletin of Earthquake Engineering, Vol. 15, No. 1, pp.339-356.

[21] Madabhushi, S. P. G., (2014) “Centrifuge Modelling for Civil Engineers”, London, Taylor \& Francis.

[22] Steedman, R.S., \& Madabhushi, S.P.G., (1991) "Wave Propagation in Sand Medium", Proceedings of $4^{\text {th }}$ International Conference on Seismic Zonation, Stanford University, Palo Alto, California, USA.

[23] Schofield, A. N., (1981) "Dynamic and Earthquake Geotechnical Centrifuge Modelling”, Proceedings of International Conference on Recent Advances in Geotechnical Earthquake Engineering and Soil Dynamics, University of Missouri-Rolla, MO, USA, pp.1081-1100.

[24] Stringer, M. E., \& Madabhushi, S. P. G., (2009) "Novel Computer-Controlled Saturation of Dynamic Centrifuge Models Using High Viscosity Fluids", Geotechnical Testing Journal, Vol. 32, No. 6, pp.559-564.

[25] Kutter, B. L., (2013) "Effects of Capillary Number, Bond Number, and Gas Solubility on Water Saturation of Sand Specimens", Canadian Geotechnical Journal, Vol. 50, No. 2, pp.133-144.

[26] Madabhushi, S. P. G., Schofield, A. N., \& Lesley, S., (1998) “A New Stored Angular Momentum (SAM) Based Earthquake Actuator”, Proceedings of Centrifuge `98, Tokyo, Japan: Balkema, pp.111-116. 
[27] Zeybek, A., \& Madabhushi, S. P. G., (2017) "Physical Modelling of Air Injection to Remediate Liquefaction", International Journal of Physical Modelling in Geotechnics, (under review).

[28] White, D. J., Take, W. A., \& Bolton, M. D., (2003) "Soil Deformation Measurement Using Particle Image Velocimetry (PIV) and Photogrammetry", Géotechnique, Vol. 53, No. 7, pp.619-631.

[29] Dashti, S., Bray, J. D., Pestana, J. M., Riemer, M., \& Wilson, D., (2010) "Mechanisms of Seismically Induced Settlement of Buildings with Shallow Foundations on Liquefiable Soil”, Journal of Geotechnical and Geoenvironmental Engineering, ASCE, Vol. 136, No. 1, pp.151-164.

[30] Elgamal, A. W., Zeghal, M., \& Parra, E., (1996) "Liquefaction of reclaimed island in Kobe, Japan”, Journal of Geotechnical and Geoenvironmental Engineering, ASCE, Vol. 122, No. 1, pp.39-49.

[31] Yasuhara, H., Kochi, M., \& Okamura, M., (2008) "Experiments and Predictions of Soil Desaturation by Air-Injection technique and the Implications mediated by Multiphase Flow Simulation", Soils and Foundations, Vol. 48, No. 6, pp.791-804.

[32] Adalier, K., Elgamal, A., Meneses, J., \& Baez, J. I., (2003) "Stone Columns as a Liquefaction Countermeasure in Non-Plastic Silty Soils", Soil Dynamics and Earthquake Engineering, Vol. 23, No. 7, pp.571-584. 
Table 1 Centrifuge test parameters and testing programme.

\begin{tabular}{llllllll}
\hline & & \multicolumn{2}{l}{ Test conditions } & & \multicolumn{2}{c}{ Earthquake parameters } \\
\cline { 3 - 8 } Test & $\begin{array}{l}\text { Model } \\
\text { ID }\end{array}$ & $\begin{array}{l}\text { Initial } \\
\text { relative } \\
\text { density }\end{array}$ & $\begin{array}{l}\text { Residual } \\
\text { degree of } \\
\text { saturation } \\
\boldsymbol{D}_{\boldsymbol{r}}(\boldsymbol{\%})\end{array}$ & $\begin{array}{l}\boldsymbol{S}_{\boldsymbol{r}}(\boldsymbol{\%}) \\
\text { Foundation } \\
\text { bearing } \\
\text { pressure } \\
\boldsymbol{q}(\mathbf{k P a})\end{array}$ & $\begin{array}{l}\text { Frequency } \\
(\mathbf{H z})\end{array}$ & $\begin{array}{l}\text { Duration } \\
(\mathbf{s})\end{array}$ & $\begin{array}{l}\text { Peak input } \\
\text { acceleration } \\
(\mathbf{g})\end{array}$ \\
FS-1 & Saturated & 40.1 & 99.0 & 135.0 & 0.72 & 28 & 0.18 \\
PS-1 & Partially saturated & 39.7 & 89.0 & 135.0 & 0.72 & 28 & 0.18 \\
PS-2 & Partially saturated & 39.8 & 86.0 & 135.0 & 0.72 & 28 & 0.18 \\
FS-2 & Saturated & 40.3 & 99.0 & Free-field & 0.72 & 28 & 0.18 \\
PS-3 & Partially saturated & 40.1 & 86.6 & Free-field & 0.72 & 28 & 0.18 \\
\hline
\end{tabular}

Table 2 Mechanisms of deformations in the partially saturated soils.

\section{During air injection}

Positive volumetric strains due to the decrease in effective stress induced by upward flow and due to the increase in the compressibility of soil matrix

Negative volumetric strains (expansion) due to the coagulation of air bubbles and upward air escape

Deviatoric
Localised and partial bearing failure due to the strength loss in the foundation soil during upward flow

\section{During and after earthquake}

Positive volumetric strains due to the increase in the compressibility of soil matrix

Limited volumetric strains due to the reconsolidation during the excess pore pressures dissipation

Limited bearing capacity failure

Limited cumulative foundation settlements due to shear deformation 


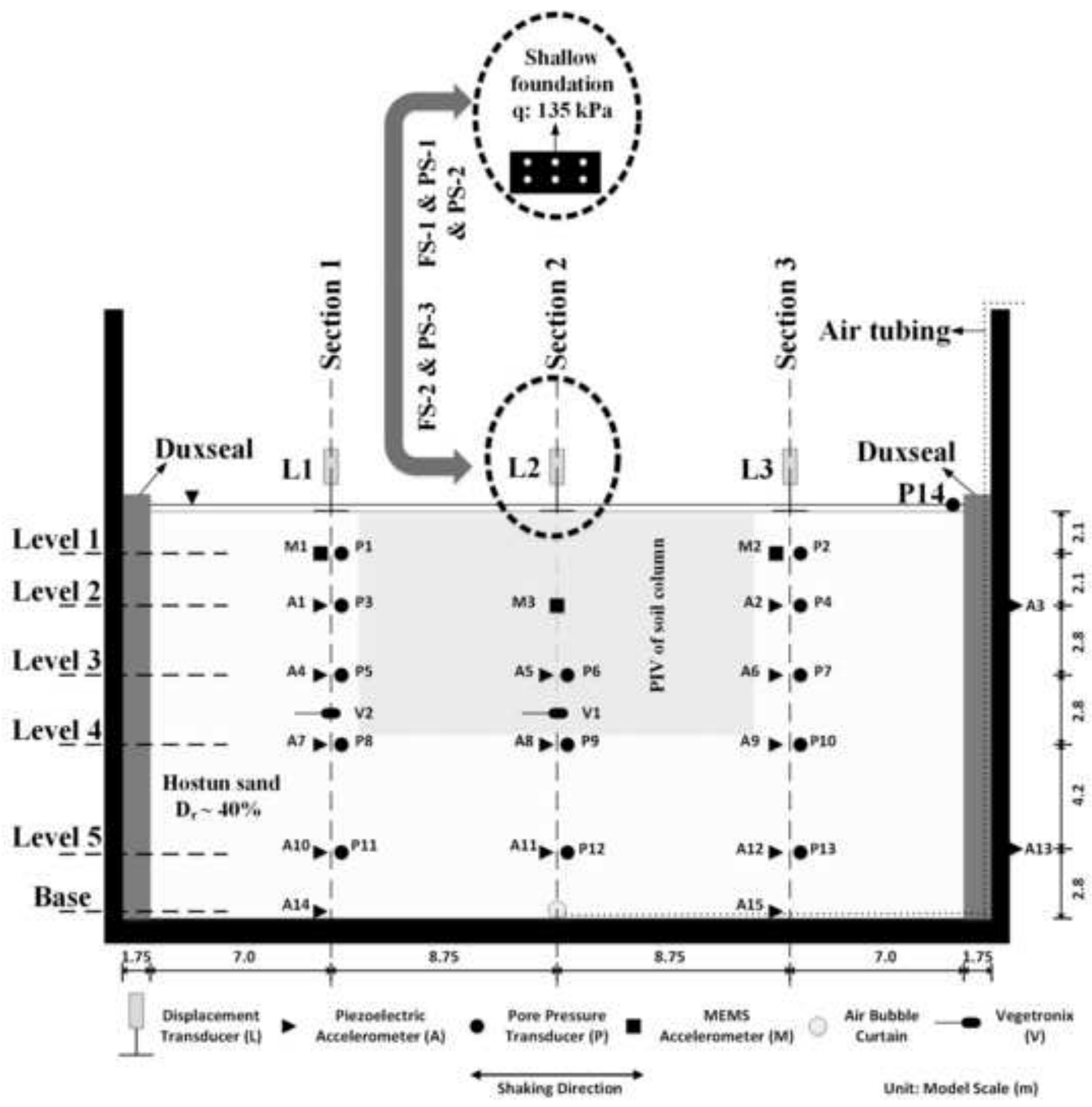



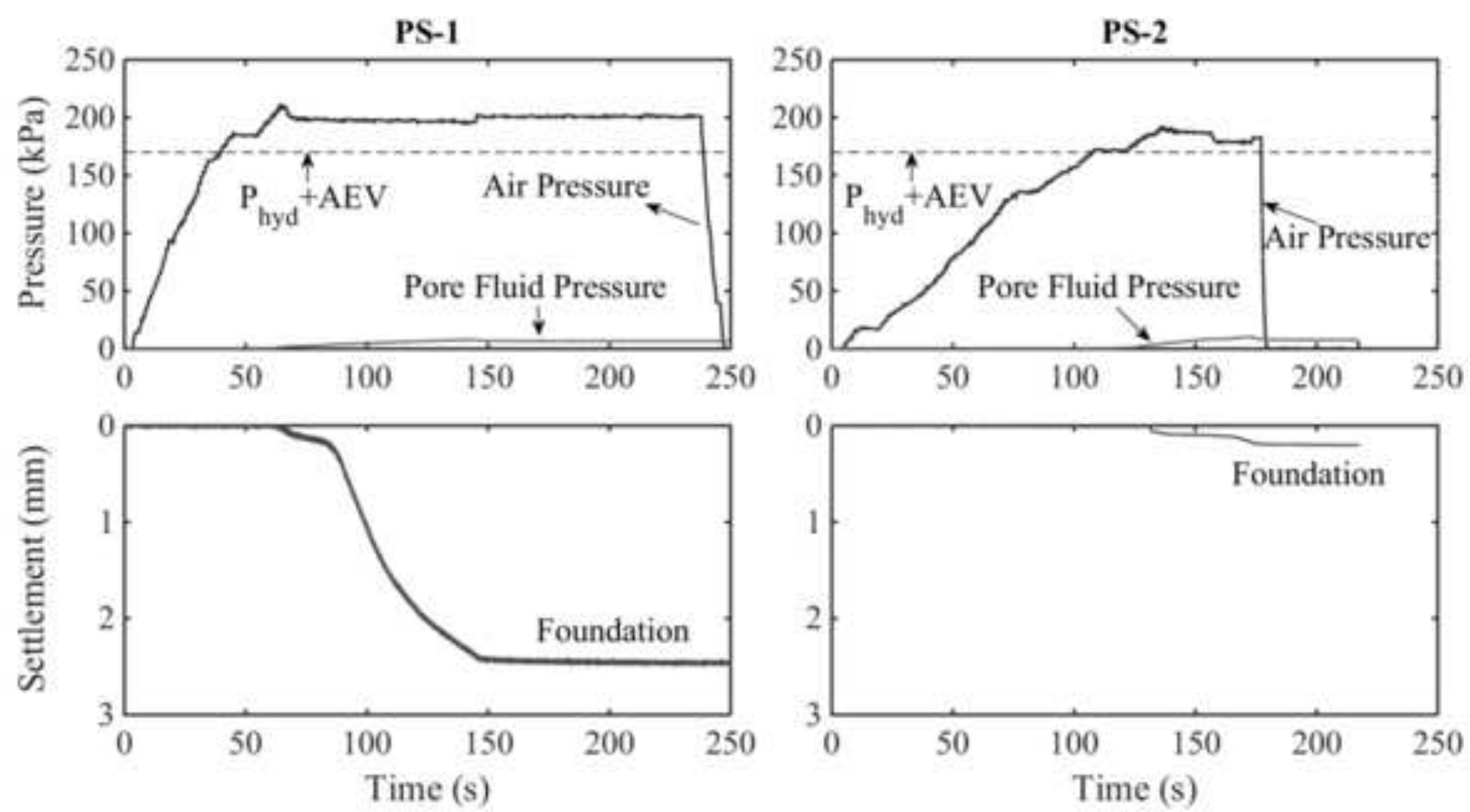


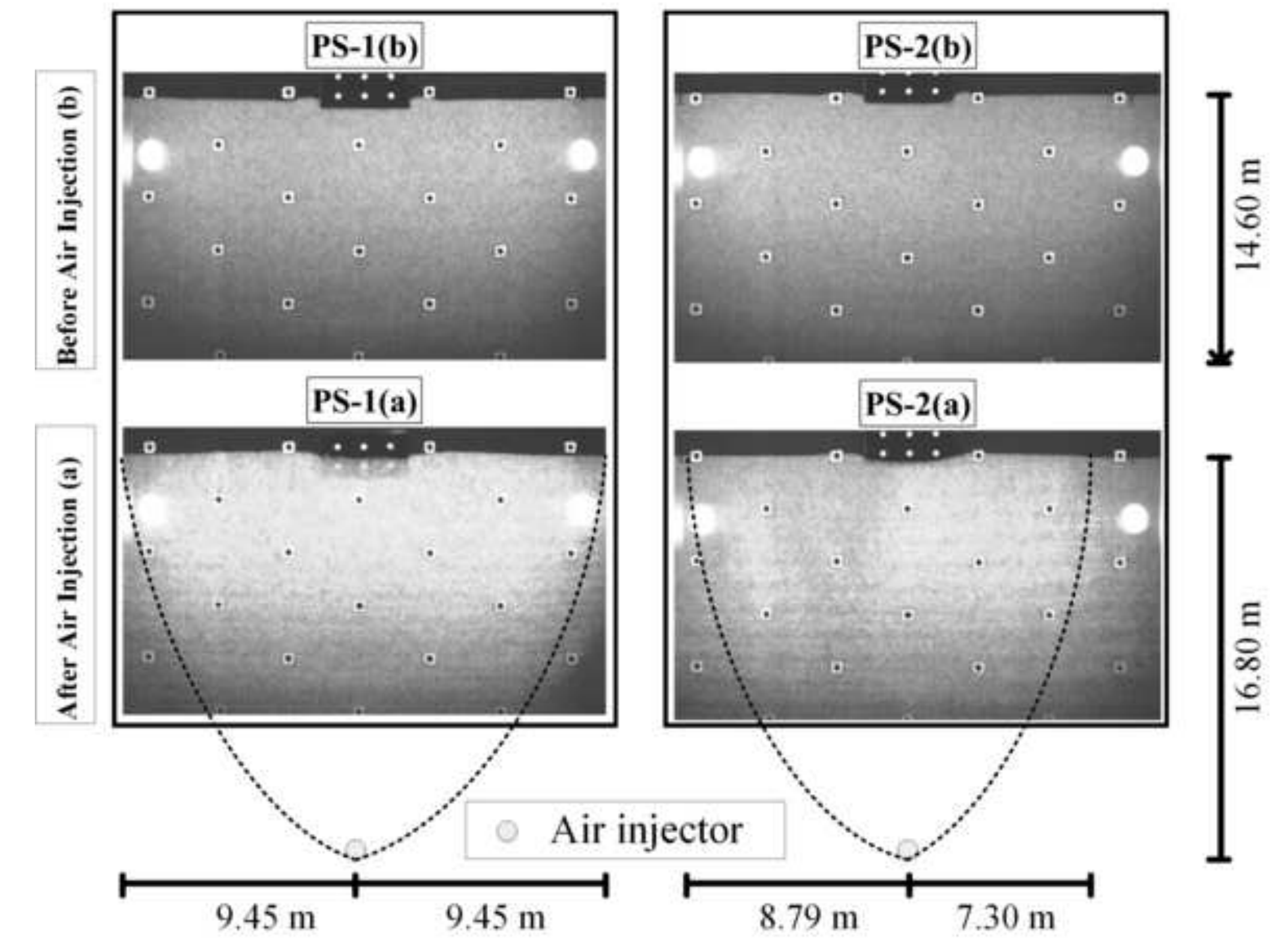


Click here to download high resolution image
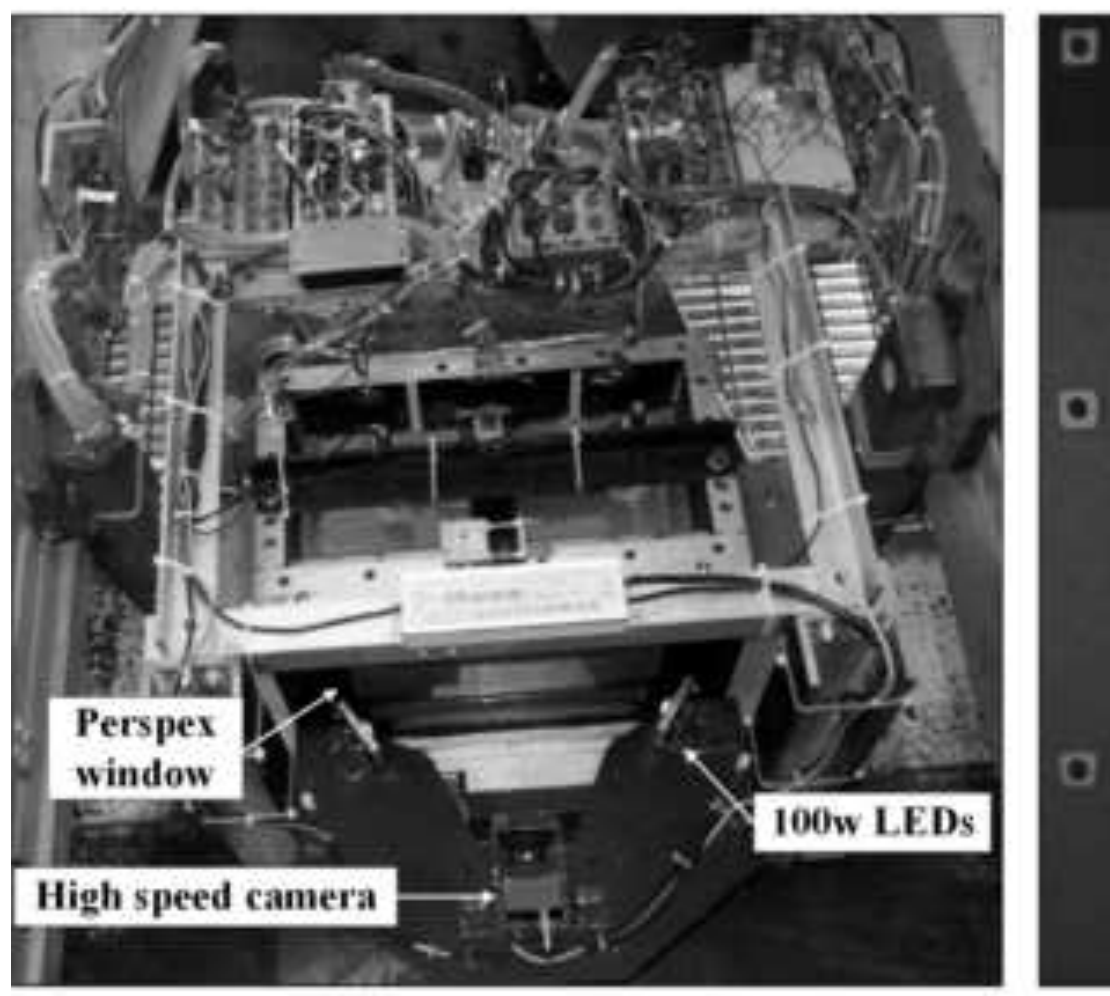
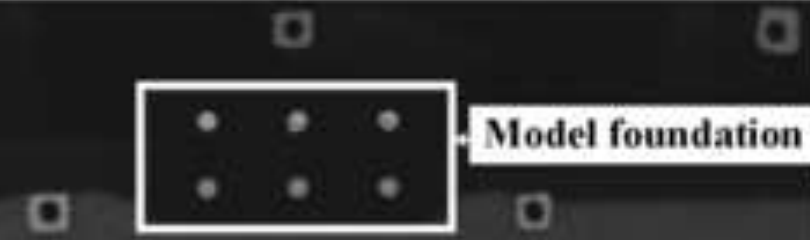

$\bullet$

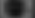

\section{Model foundation} 0

$\bullet$

e

$\leftarrow$ Sand body

$$
\text { Control markers }
$$


Free-Field Tests (Section 1)
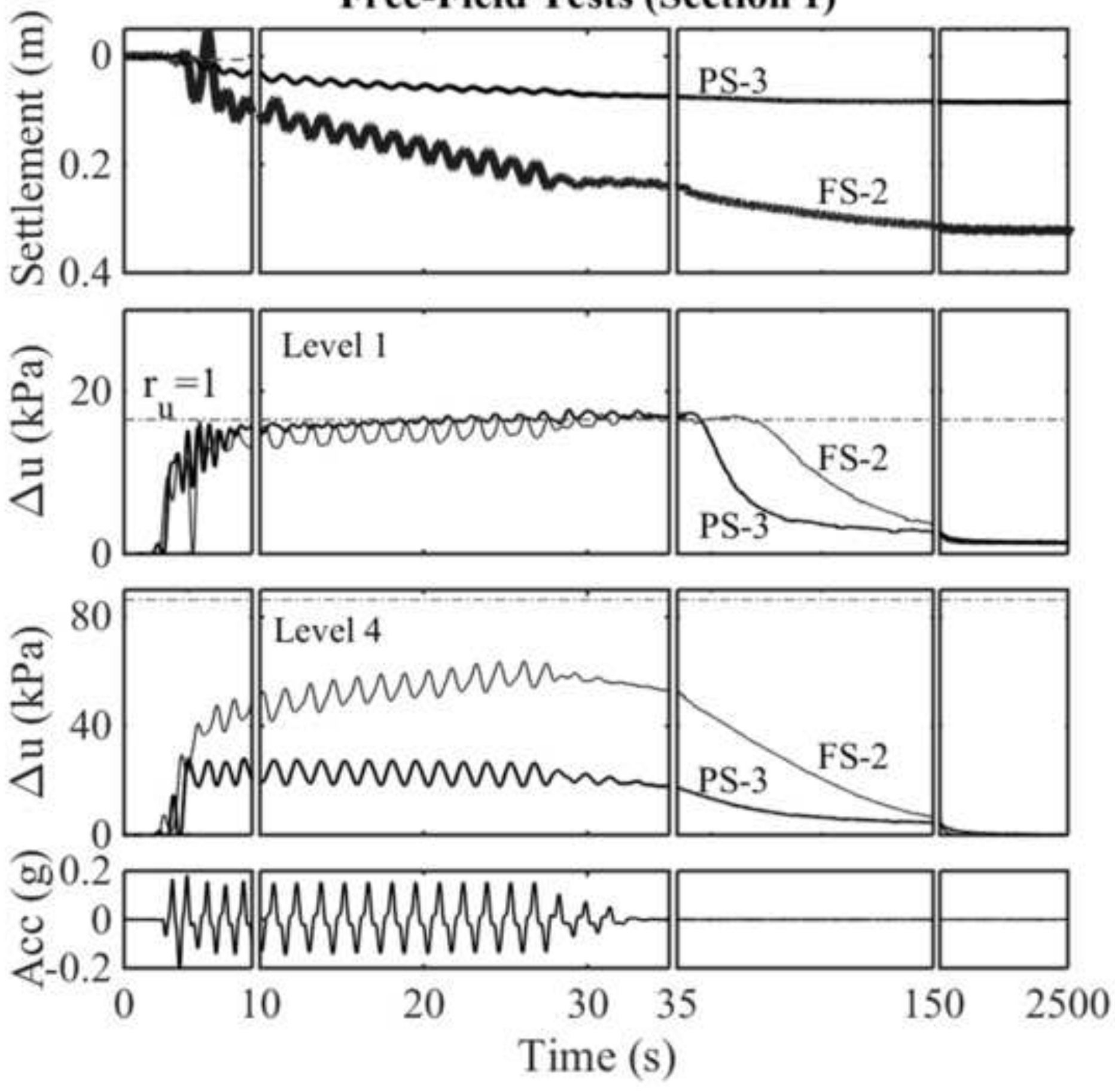
Click here to download high resolution image
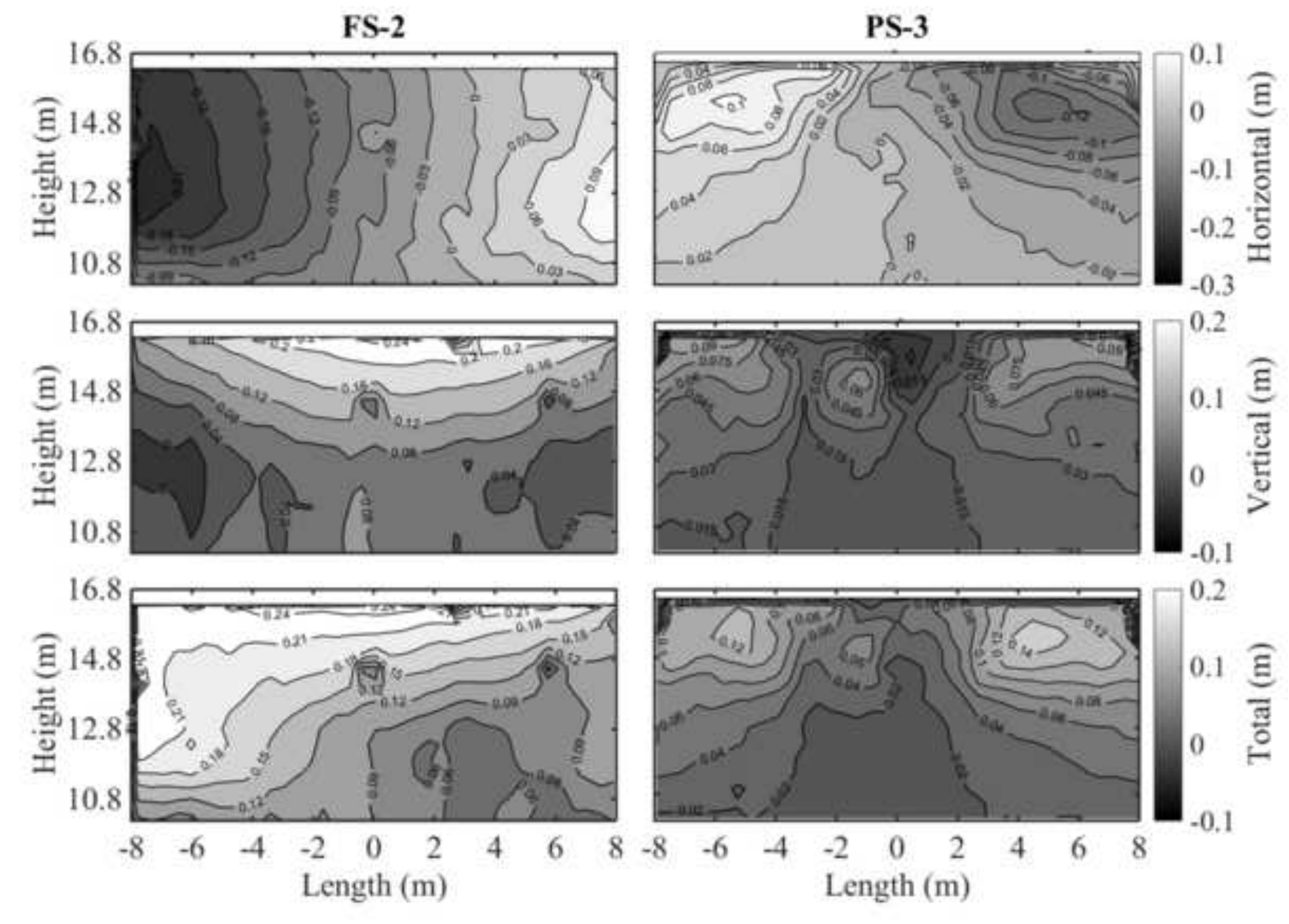

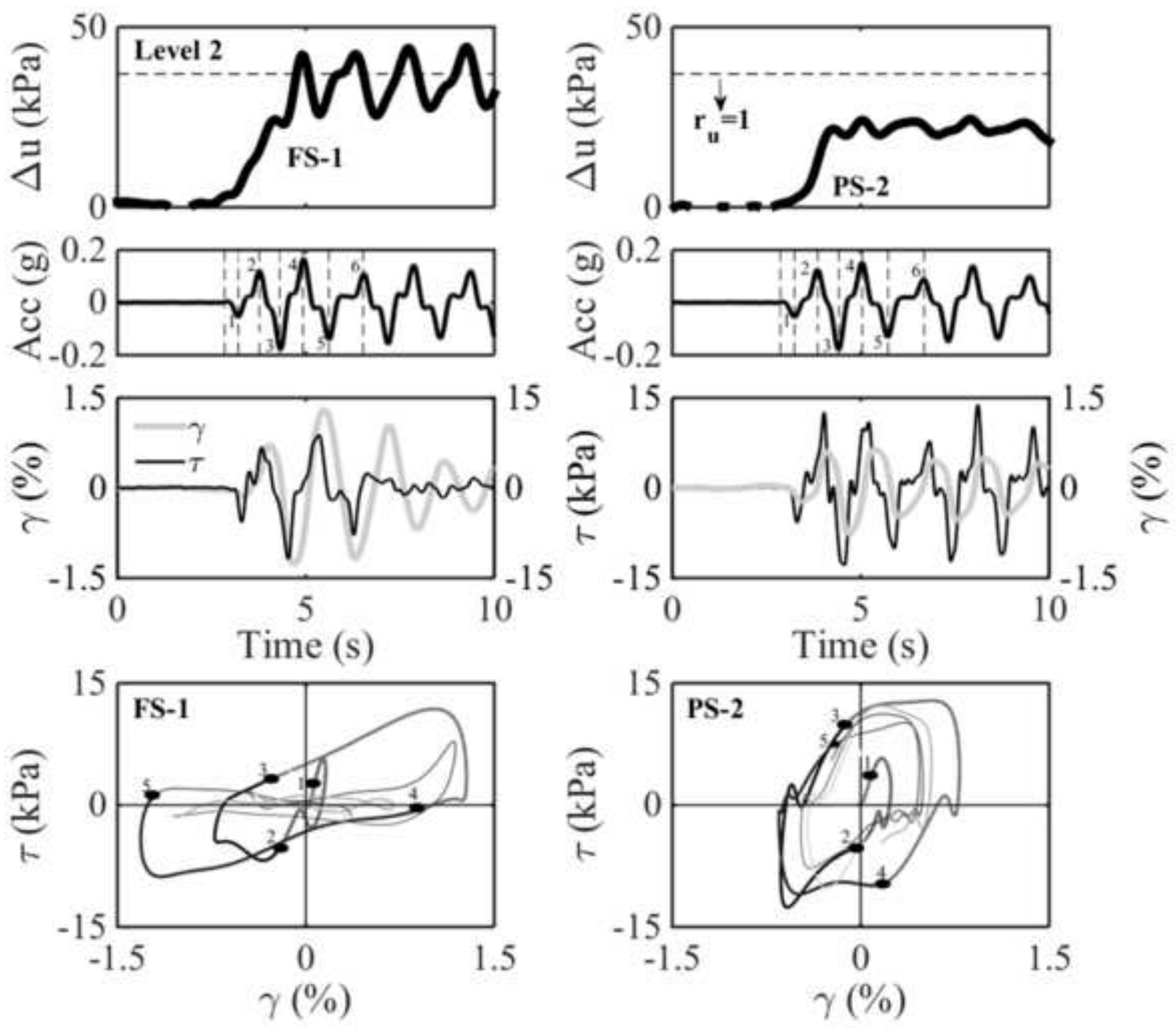


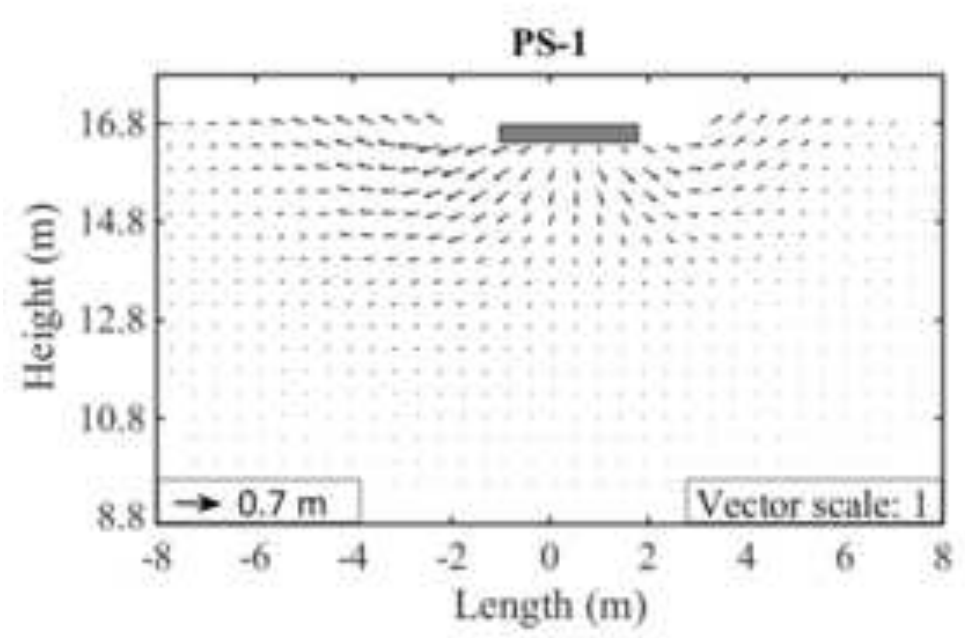

Horizontal Displacement (m) Vertical Displacement (m)

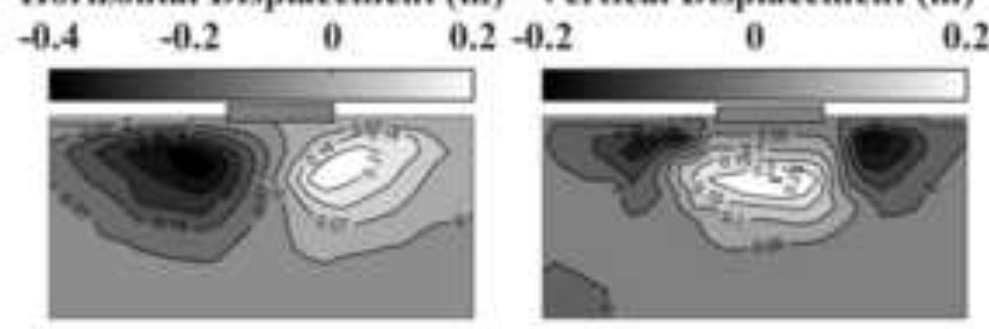

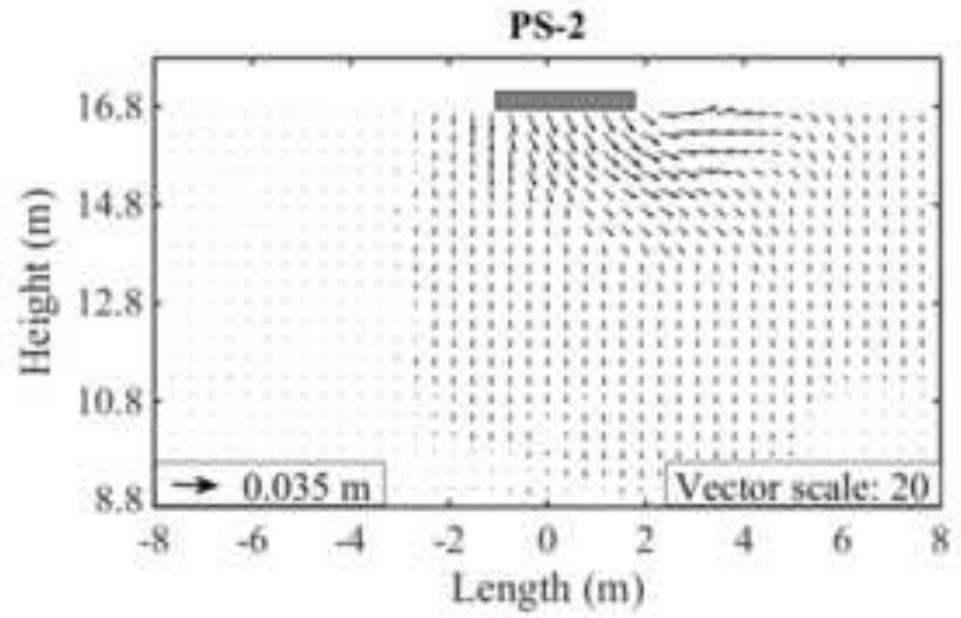

Horizontal Displacement (m) Vertical Displacement (m) $\begin{array}{lllllll}-0.05 & -0.025 & 0 & 0.025 & -0.025 & 0 & 0.025\end{array}$

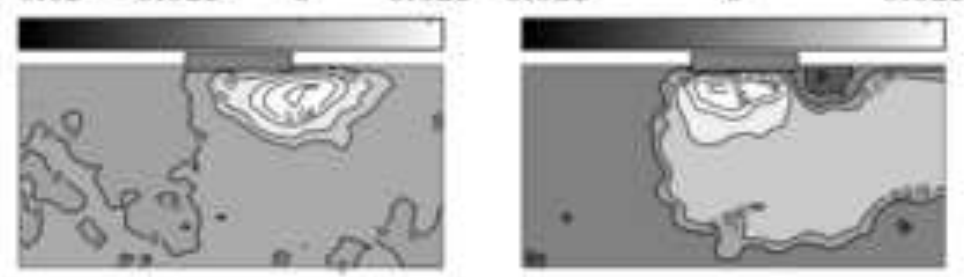




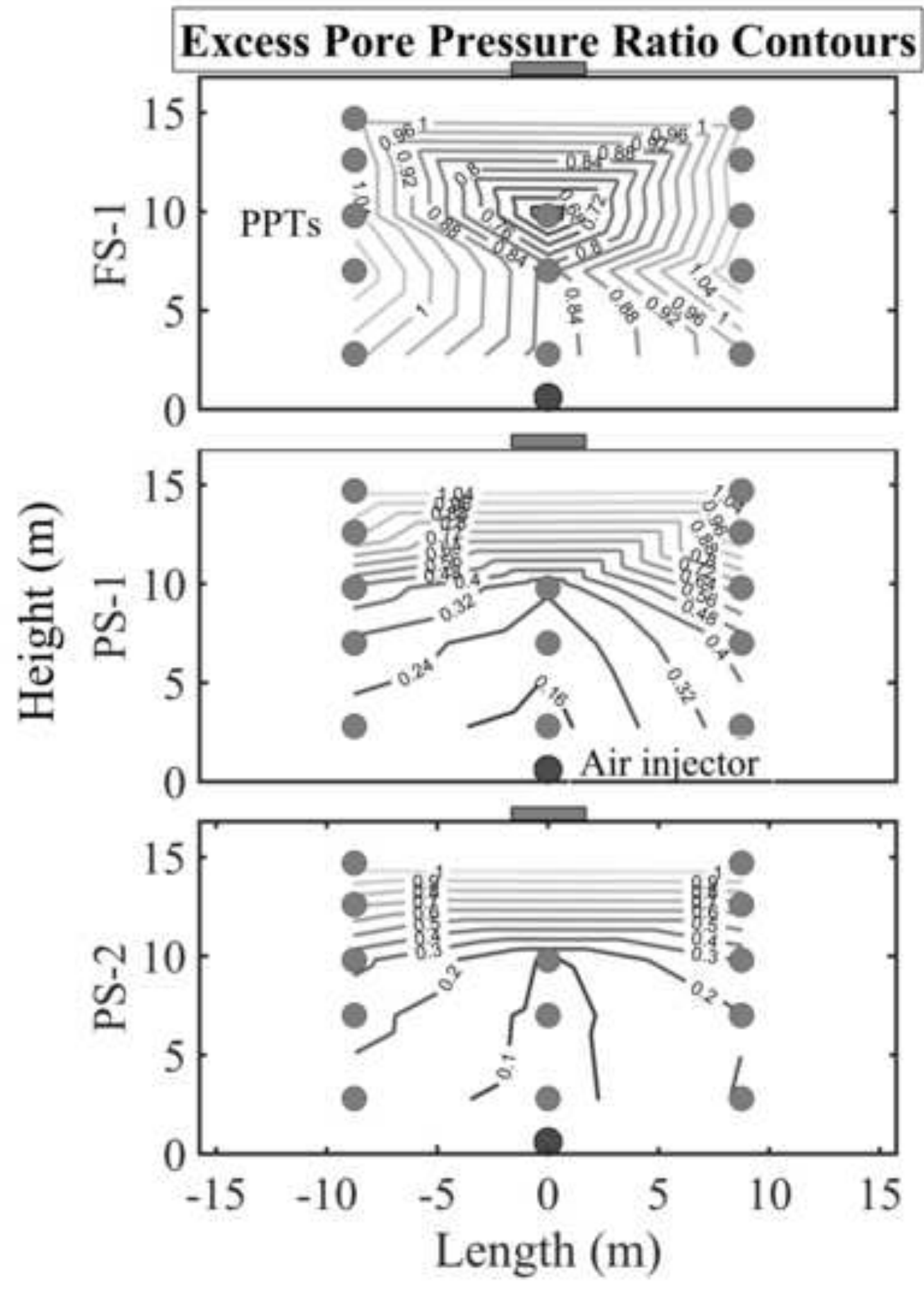



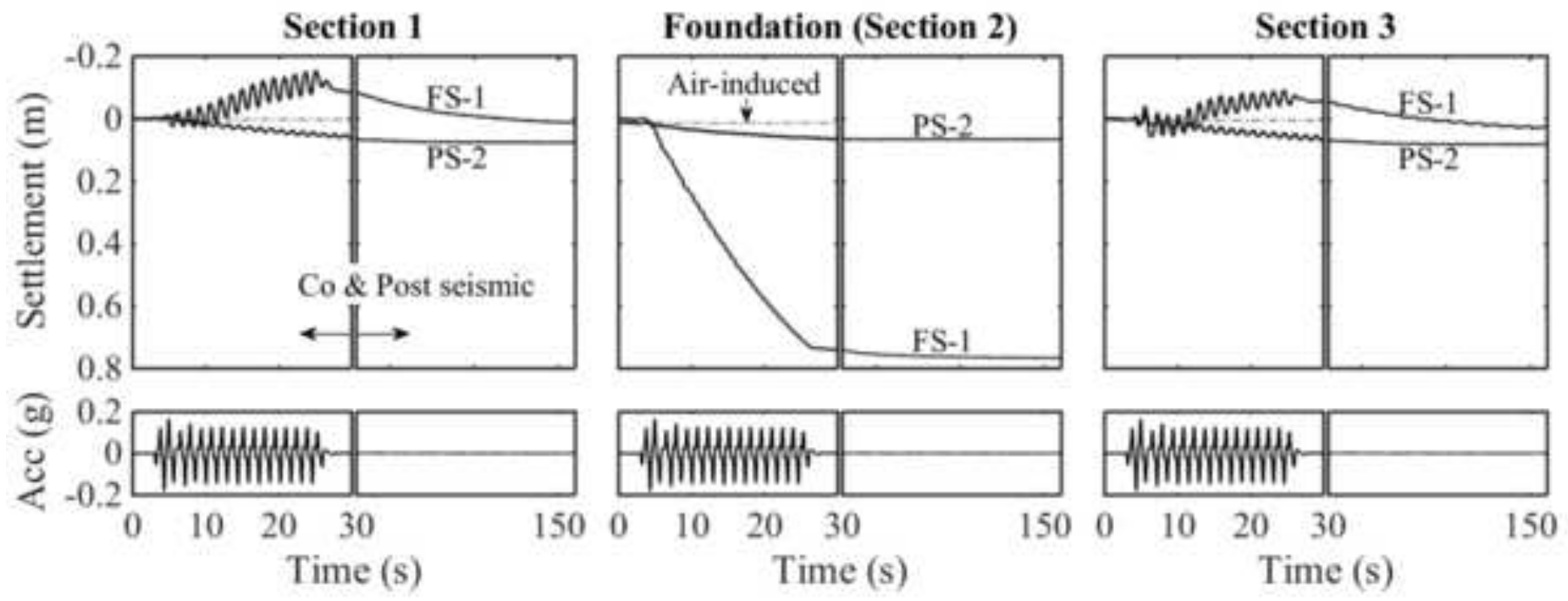
Click here to download high resolution image
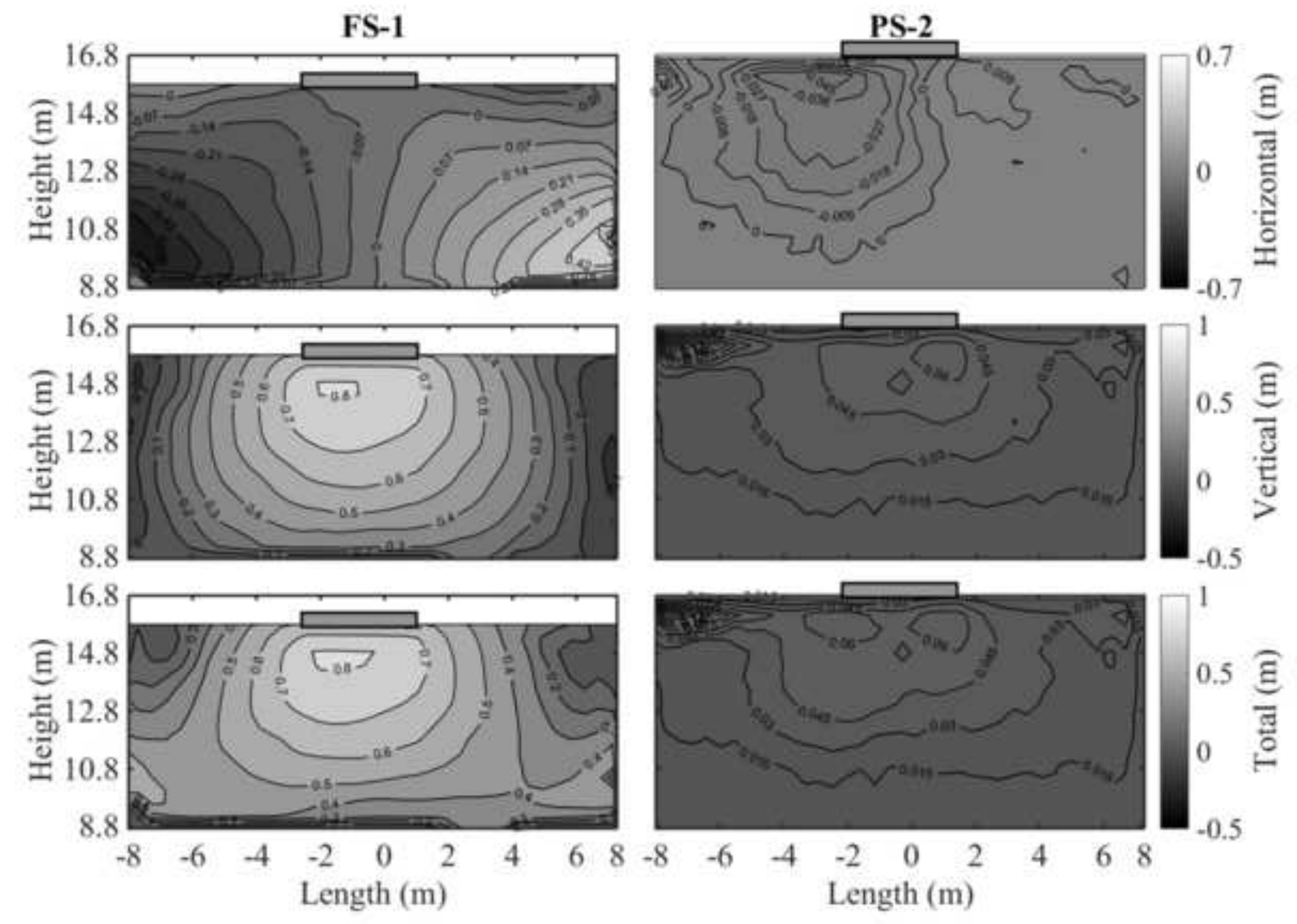

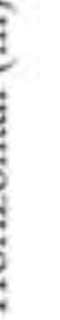



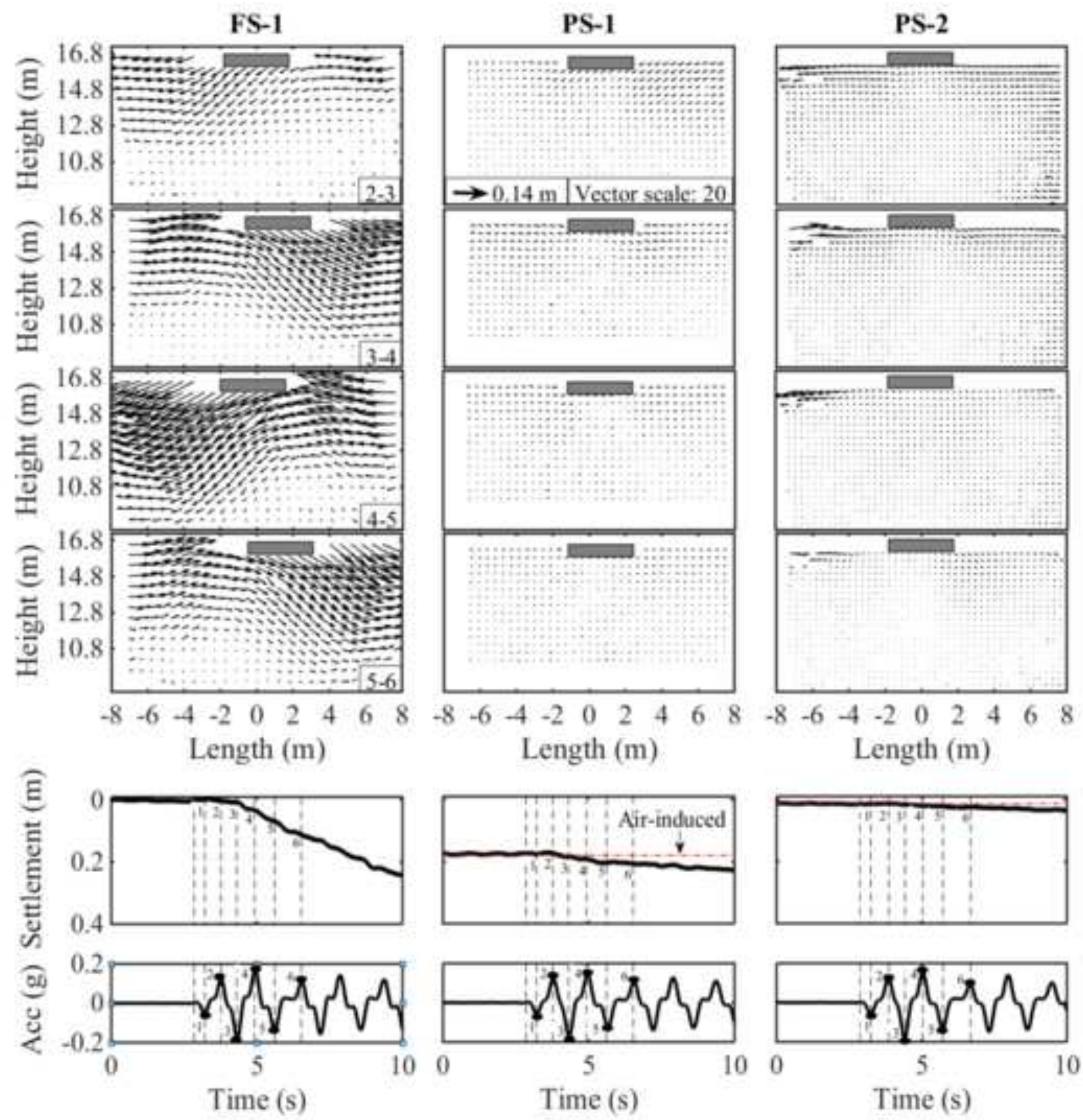
Supplementary Material
Click here to download Supplementary Material: Captions_R3.docx

Supplementary Material
Click here to download Supplementary Material: Captions_R3.docx

X

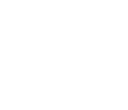

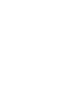

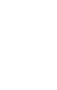

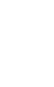
.

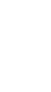
. .

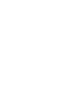

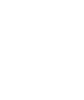
.

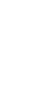

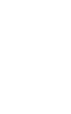
. . .

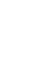
(2) .

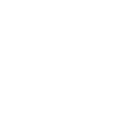
$\left(\frac{10}{0}\right.$

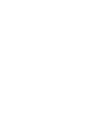

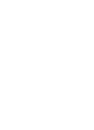

